\title{
Antagonistic Functions of Dishevelleds Regulate Frizzled3 Endocytosis via Filopodia Tips in Wnt-Mediated Growth Cone Guidance
}

\author{
Keisuke Onishi, ${ }^{1}$ Beth Shafer, ${ }^{1}$ Charles Lo, ${ }^{1}$ Fadel Tissir, ${ }^{2}$ Andre M. Goffinet,${ }^{2}$ and Yimin Zou ${ }^{1}$ \\ ${ }^{1}$ Neurobiology Section, Biological Sciences Division University of California, San Diego, La Jolla, California 92093 and ${ }^{2}$ Université Catholique de Louvain, \\ Institute of Neuroscience, Brussels, B-1348 Belgium
}

\begin{abstract}
How growth cones detect small concentration differences of guidance cues for correct steering remains a long-standing puzzle. Commissural axons engage planar cell polarity (PCP) signaling components to turn anteriorly in a Wnt gradient after midline crossing. We found here that Frizzled3, a Wnt receptor, undergoes endocytosis via filopodia tips. Wnt5a increases Frizzled3 endocytosis, which correlates with filopodia elongation. We discovered an unexpected antagonism between Dishevelleds, which may function as a signal amplification mechanism in filopodia where PCP signaling is activated: Dishevelled2 blocks Dishevelled1-induced Frizzled3 hyperphosphorylation and membrane accumulation. A key component of apical-basal polarity (A-BP) signaling, aPKC, also inhibits Dishevelled1-induced Frizzled3 hyperphosphorylation. Celsr3, another PCP component, is required in commissural neurons for anterior turning. Frizzled3 hyperphosphorylation is increased in Celsr3 mutant mice, where PCP signaling is impaired, suggesting Frizzled3 hyperphosphorylation does correlate with loss of PCP signaling in vivo. Furthermore, we found that the small GTPase, Arf6, which is required for Frizzled3 endocytosis, is essential for Wnt-promoted outgrowth, highlighting the importance of Frizzled3 recycling in PCP signaling in growth cone guidance. In a Wnt5a gradient, more Frizzled 3 endocytosis and activation of atypical protein kinase $\mathrm{C}$ was observed on the side of growth cones facing higher Wnt5a concentration, suggesting that spatially controlled Frizzled 3 endocytosis is part of the key mechanism for growth cone steering.
\end{abstract}

\section{Introduction}

In stark contrast to our rich knowledge on the molecular identity of axon guidance cues, the logic of growth cone signaling leading to directionality remains fragmentary (Bashaw and Klein, 2010). Wnt-Frizzled signaling is essential for anterior turning of spinal cord commissural axons after midline crossing and is an excellent model for studying growth cone steering mechanisms (Lyuksyutova et al., 2003). Members of apical-basal polarity (A-BP) and planar cell polarity (PCP) signaling, atypical protein kinase $\mathrm{C}$ (aPKC), Frizzled3, Vangl2, Ceslr3, and Dishevelled1, have been shown to be required in mediating Wnt attraction and anterior turning (Wolf et al., 2008; Shafer et al., 2011), suggesting that cell polarity signaling pathways play a central role in polarizing growth cones right after midline crossing. How PCP and A-BP

\footnotetext{
Received July 1, 2013; revised Sept. 2, 2013; accepted Sept. 28, 2013.

Author contributions: Y.Z. designed research; K.O. performed research; B.S., C.L., F.T., and A.M.G. contributed unpublished reagents/analytic tools; K.O. and Y.Z. analyzed data; K.O. and Y.Z. wrote the paper.

This work was supported by an National Institutes of Health (NIH) R01 (NS047484) to Y.Z., a postdoctoral Fellowship from Japan Society for Promotion of Sciences to K.0., a postdoctoral Fellowship from Spinal Cord Research Foundation of Paralyzed Veterans of America to C.L., and a postdoctoral Fellowship from NIH/National Institute of Neurological Disorders and Stroke training grant (T32 NS007220-27) to C.L. We thank Jim Casanova for his generous gifts of the Arf6 wild-type and mutant constructs and Sourav Ghosh for Par6 constructs. We thank Zou lab members Edmund Hollis II, Anna Tury, Sonal Thakar, Virginia Hazen, Liqing Wang, John Scott, and Alex Goetz for critical reading of this manuscript and helpful comments.

Correspondence should be addressed to Yimin Zou, Neurobiology Section, Biological Sciences Division, University of California, San Diego, La Jolla, CA 92093. E-mail: yzou@ucsd.edu.

DOI:10.1523/JNEUROSCI.2800-13.2013

Copyright $\odot 2013$ the authors $\quad 0270-6474 / 13 / 3319071-15 \$ 15.00 / 0$
}

signaling pathways function to steer growth cones is not well understood.

We found the Wnt-binding receptor Frizzled 3 undergoes endocytosis via the tips of growth cone filopodia. Wnt5a promotes endocytosis of Frizzled3, which is mediated by Arf6, a small GTPase, to stimulate Wnt-stimulated outgrowth. We uncovered a novel difference among the three Dishevelleds. While Dishevelled1 induces Frizzzled3 hyperphosphorylation and membrane accumulation, Dishevelled2 does not; instead, Dishevelled2 prevents Dishevelled1 from inducing Frizzled3 hyperphosphorylation. The activation of Dishevelled2 may cause the release of inhibition Dishevelled1 has on Frizzled3 endocytosis to allow for amplification of PCP signaling in a select set of filopodia. Consistent with these results, in a Wnt5a gradient, more Frizzled 3 endocytosis and activation of aPKC were observed on the side facing higher Wnt5a concentration. We propose that the integrated functions of PCP and A-BP signaling pathways endow the growth cones with high sensitivity for guidance cues to control the direction of turning.

\section{Materials and Methods}

Plasmids, reagents, and antibodies. Mouse Frizzled3 was subcloned into C-terminal tdTomato tag expression vectors (modified pCAGEN). FLAG sequences were inserted between 24 and 25 aa in the $\mathrm{N}$ terminal (following the predicted signal peptide sequences;1-22) of mouse Frizzled3. Frizzled3-HA, Dishevelled1-FLAG, Dishevelled1-EGFP, and Dishevelled2-FLAG expressing constructs are described previously 
(Shafer et al., 2011). Dishevelled3 was amplified from mouse E16.5 brain cDNA library and subcloned into C-terminal FLAG tag expression vector (pZou-FLAG). aPKC constructs were described previously (Wolf et al., 2008). PAR6 expression vector was kindly provided by Dr. Sourav Ghosh. Hemagglutinin (HA)-tagged Arf6 WT, T27N, T157, and EGFPRab11 constructs were kindly given by Dr. James E. Casanova. EGFPRab4, 5, and 8 constructs were a kind gift from Dr. Johan Peranen. To make EGFP-tagged Arf6 series, Arf6 WT, T27N, and T157 were amplified by PCR from HA-tagged Arf6 series and subcloned into pEGFP-N2.1 ( $\beta$-actin promoter; modified from pEGFP-N2; Clontech). All constructs were verified by sequencing (Eton Biosciences).

Sequences of the shRNA constructs are as follows: control shRNA ( $5^{\prime}$-GA AACGGAAAGCAGGTACG-3'), human Dishevelled1 shRNA (5'-CAGT CTGAAAGTACGTGGA-3'), human Dishevelled2 shRNA (5'-TG TGACCTCCTCCTCCAGT-3'). Complementary oligonucleotides were annealed and inserted into pSuper-retro-neo-GFP. The plasmid encoding shRNA against rat Arf6 (target sequence; 5'-CCTCATCTTCGCCAACAA GCAGGACCTGC-3') and control shRNA plasmid (TR30008) were purchased from Origene (pGFP-V-RS vector). All constructs were verified by sequencing (Eton Bioscience).

Recombinant Wnt5a was purchased from R\&D Systems, and Sulfo-NHSLC-Biotin and NeutrAvidin agarose were from Pierce. The primary antibodies used in this study include anti-Frizzled3 (R\&D Systems), anti- $\alpha$-Adaptin (BD Transduction Laboratories), anti-Amphiphysin (BD Transduction Laboratories), anti-AP180 (BD Transduction Laboratories), anti-FLAG

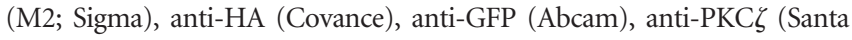
Cruz Biotechnology), anti-pPKC $\zeta$ (T410; Santa Cruz Biotechnology), antiRac1 (BD Transduction Laboratories), anti-phospho-c-Jun (Ser63; Cell Signaling Technology), anti-c-Jun (Cell Signaling Technology), anti-phosphoJNK (Thr183/Tyr185; Cell Signaling Technology), anti-JNK (Cell Signaling Technology), anti-Dishevelled1 (Santa Cruz Biotechnology), anti-Dishevelled2 (Cell Signaling Technology), anti-GAPDH (Millipore), anti-Insulin Receptor $\beta$ (Santa Cruz Biotechnology), anti-TAG-1 (Developmental Studies Hybridoma Bank), and anti-L1 (Developmental Studies Hybridoma Bank). Anti-Frizzled3 antibodies for immunoblotting were kindly provided by Dr. Yanshu Wang and Dr. Jeremy Nathans (Wang et al., 2006). Alexa Fluor-conjugated secondary antibodies for mouse/rabbit/rat IgG and mouse IgM were purchased from Invitrogen. Horseradish peroxidaseconjugated secondary antibodies for mouse/rabbit/goat IgG were purchased from Jackson ImmunoResearch. Anti-Celsr3 rabbit polyclonal antibodies were generated in the Zou lab (Fenstermaker et al., 2010).

Commissural neuron culture and time-lapse imaging. Rat E13 and mouse E11.5 embryos of either sex were dissected and commissural neuron culture was prepared as previously described (Wolf et al., 2008; Shafer et al., 2011). Dissociated commissural neurons were plated in a $35 \mathrm{~mm}$ glass-bottom dish (MatTek) coated with $20 \mu \mathrm{g} / \mathrm{ml}$ PDL for time-lapse imaging or 24-well dish coated with PDL for immunocytochemistry. Electroporations of rat E13 spinal cords were performed as described previously (Wolf et al., 2008). Time-lapse imaging was performed using Olympus IX81 inverted microscope and PerkinElmer UltraView Vox Spinning Disk Confocal system (Shafer et al., 2011). Images of the growth cones were obtained every $3 \mathrm{~s}$ for $5 \mathrm{~min}$. Before taking images, neurons were incubated with Alexa Fluor 488-conjugated anti-FLAG antibodies for $15 \mathrm{~min}$ and then washed to remove unbound anti-FLAG antibodies. Subsequently neurons were treated with Wnt5a $(100 \mathrm{ng} / \mathrm{ml})$ to analyze the effects on the direction of Frizzled 3 vesicle movement. Frizzled3tdTomato vesicles are tracked manually in 14 growth cones, 48 filopodia, 298 vesicles for WT, 11 growth cones, 37 filopodia, 213 vesicles for WT with Wnt5a, 9 growth cones, 21 filopodia, 101 vesicles for 7A, 5 growth cones, 20 filopodia, and 78 vesicles for $7 \mathrm{~A}$ with Wnt5a. Images were acquired using Volocity software (PerkinElmer). To investigate Arf6EGFP movement, a total of 41 growing filopodia and 28 shrinking filopodia from six growth cones were analyzed and quantified.

Measurement of FLAG-Frizzled3-tdTomato intensity. To quantify the Frizzled 3 cell-surface amount in commissural neurons, rat commissural neurons expressing FLAG-Frizzled3 WT or 7A-tdTomato were incubated with Alexa Fluor 488-conjugated anti-FLAG antibodies for $15 \mathrm{~min}$. After washing out unbound anti-FLAG antibodies, neurons were fixed with $4 \%$ paraformaldehyde (PFA) for $15 \mathrm{~min}$ at $37^{\circ} \mathrm{C}$, washed again, and then immediately mounted. Images were taken using a Zeiss LSM 510 confocal microscope, and analyzed using ImageJ software. Fifteen growth cones for each condition from three independent experiments were analyzed.

Quantification of Frizzled 3 colocalization with AP-2 at the tips of filopodia. Commissural neuron cultures were treated with or without 100 $\mathrm{ng} / \mathrm{ml} \mathrm{Wnt} 5$ a for $5 \mathrm{~min}$, followed by $4 \%$ PFA fixation for $15 \mathrm{~min}$ at $37^{\circ} \mathrm{C}$. Cells were then immunostained with anti-Frizzled3 (R\&D Systems) and anti- $\alpha$-Adaptin (BD Transduction Laboratories). Growth cone images were taken by using Zeiss LSM510, and colocalization was quantified manually.

Wnt5a gradient in Dunn chamber. For Dunn chamber assays, primary commissural neurons were grown on appropriately coated $18 \mathrm{~mm}$ square coverslips (Fisher Scientific) at a low density such that individual isolated neurons were present $(150,000$ cells/well in a 6-well plate for commissural neurons). The Dunn chamber assembly protocol was described previously (Yam et al., 2009). The Dunn chambers were prewashed twice with conditioned media. Conditioned media was added to fill the inner and outer wells. A coverslip with neurons was inverted over the Dunn chamber, leaving a narrow slit at the edge for draining and refilling the outer well. Excess media was removed by paper, and three sides of the Dunn chamber were sealed with hot paraffin:vaseline. Using a piece of paper towel, all the liquid from the outer well was removed through the filling slit, and the Wnt5a (100 ng/ml; diluted in conditioned media) was added to the outer well by using a $1 \mathrm{cc}$ insulin syringe. The filling slit was then sealed with hot paraffin:vaseline. Dunn chambers were assembled rapidly ( $<5 \mathrm{~min}$ ) to avoid changes in the $\mathrm{pH}$ of the media. After assembly, the Dunn chamber was put back into $37^{\circ} \mathrm{CCO}_{2}$ incubator for $30 \mathrm{~min}$. Then the coverslip was immediately removed from the Dunn chamber and put into $4 \%$ PFA solution for $15 \mathrm{~min}$ at $37^{\circ} \mathrm{C}$ for fixation followed by immunostaining.

To quantify Fzd3/AP-2 colocalization and p-aPKC localization, only the growth cones that direct perpendicularly to the Wnt5a gradient were analyzed. The line was drawn at the middle of the growth cone and then Fzd3 and AP-2 colocalization in the proximal side and distal side were counted manually. Using ImageJ, $\mathrm{p}-\mathrm{PKC} \zeta$ intensity was measured and divided by the area of proximal or distal side to normalize. Then P/D ratio was calculated. For Fzd3/AP-2 colocalization, we analyzed 38 growth cones (bovine serum albumin (BSA) control) and 39 growth cones (Wnt5a) from four independent experiments. For p-PKC $\zeta$ intensity, we analyzed 29 growth cones (BSA control) and 29 growth cones (Wnt5a gradient) from three independent experiments.

Glutathione S-transferase-pull-down assay, surface biotinylation, avidin precipitation, Rac activation assay, immunoprecipitation, phosphatase/glycosidase assay, and biochemical analyses. Glutathione $S$-transferase (GST) or GST fusion of the cytoplasmic region of Frizzled3 (GST-Fzd3cyto; 505-666 aa) were generated using pGEX4T-1. All GST fusions were expressed in BL21 Escherichia coli and purified with glutathioneSepharose 4B (GSH beads; GE Healthcare). The whole-brain lysates were prepared from WT mouse P14 brains. P14 brains were homogenized and lysed with pull-down buffer (20 mm Tris $\mathrm{HCl}, \mathrm{pH} 7.4,150 \mathrm{~mm} \mathrm{NaCl}, 1$ mм EDTA, 1 mм EGTA, 5 mм NaF, 10 mм $\beta$-glycerophosphate, $1 \mathrm{~mm}$ $\mathrm{Na}_{3} \mathrm{VO}_{4}, 1 \mathrm{~mm}$ dithiothreitol, and protease inhibitor cocktail and $0.5 \%$ TX-100). GST fusion proteins $(20 \mathrm{mg}$ ) immobilized with GSH beads were combined with whole-brain extract $(\sim 1 \mathrm{mg})$ in the pull-down buffer. After incubation for $1 \mathrm{~h}$ on a rotating wheel at $4^{\circ} \mathrm{C}$, beads were separated from the supernatant by centrifugation and washed three times in the TBS-T ( $0.1 \%$ Tween 20$)$, and the proteins retained on the beads (not including the GST fusions) were analyzed by Western blotting.

Cell-surface biotinylation and avidin precipitation were performed as described previously (Shafer et al., 2011). After $24 \mathrm{~h}$ of transfection (FuGENE6; Roche), cell-surface proteins were labeled with $1 \mathrm{mg} / \mathrm{ml}$ SulfoNHS-LC-Biotin on ice for $45 \mathrm{~min}$. After quenching active biotin by glycine, the cell lysates were incubated with NeutrAvidin agarose for $1 \mathrm{~h}$ and then precipitated. The total extract and avidin-bound fraction were analyzed by Western blotting. To do phosphatase and glycosidase assay, avidin-bound fractions were treated with BSA or alkaline phosphatase (Roche) for $60 \mathrm{~min}$ at $37^{\circ} \mathrm{C}$. Then the samples were boiled with denaturing solution (NEB) and treated with BSA or PNGase F (NEB) for 
$60 \mathrm{~min}$ at $37^{\circ} \mathrm{C}$. Samples were then boiled again and subjected to immunoblotting.

Activation of Rac1 was assayed using GST-CRIB. After HEK293 cells were incubated in serum-free DMEM for $24 \mathrm{~h}$, the cells were stimulated

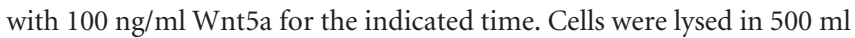
Rac pull-down buffer (20 mm Tris-HCl, pH 7.4, $150 \mathrm{~mm} \mathrm{NaCl}, 10 \mathrm{~mm}$ $\mathrm{MgCl}_{2}, 1 \% \mathrm{NP}-40,10 \%$ glycerol, and protease inhibitor). Lysates were incubated with GST-CRIB immobilized glutathione-Sepharose $(20 \mu \mathrm{g}$ GST-CRIB $/ 10 \mu \mathrm{l} \mathrm{GSH}$-Sepharose) for $1 \mathrm{~h}$ at $4^{\circ} \mathrm{C}$. Glutathione-Sepharose was precipitated by centrifugation, washed with TBS-T $(0.05 \%$ Tween $20)$ three times, boiled, and then analyzed by Western blotting. For immunoprecipitation assay, cell lysates were incubated with the indicated antibodies for $1 \mathrm{~h}$ at $4^{\circ} \mathrm{C}$, then protein $\mathrm{A} / \mathrm{G}$ plus agarose (Santa Cruz Biotechnology) was added and rotated for $1 \mathrm{~h}$ at $4^{\circ} \mathrm{C}$. Agarose was precipitated by centrifugation, washed with TBS-T $(0.05 \%$ Tween 20$)$ three times, boiled, and then analyzed by Western blotting.

All biochemical experiments in figures were performed at least three times and all images are representatives.

Mouse lines. Celsr 3 mutant and floxed mice were generated by Dr Andre Goffinet. Wnt1-Cre transgenic mice were purchased from The Jackson Laboratory. To produce Wnt1-Cre driven Celsr 3 conditional knock-out mice, Wnt1-Cre transgenic mice were mated with heterozygous mice carrying the Celsr $3^{f l o x}$ allele. Subsequently they were mated with mice homozygous for the Celsr $3^{\text {flox }}$ allele $\left(\mathrm{Celsr} 3^{\text {flox }}{ }^{\text {flox }}\right)$ to obtain embryos of either sex with Celsr $3^{\text {flox/flox }}$;Wnt1-Cre genotype. Genotyping of all animals was done by PCR using genomic DNA prepared from tails. Experiments were conducted in accordance with the National Institutes of Health Guide for the Care and Use of Laboratory Animals and approved by the University of California San Diego Animal Subjects Committee.

Immunohistochemistry. E11.5 mouse embryos were fixed in 4\% PFA for $2 \mathrm{~h}$ on ice. After equilibration with $30 \%(\mathrm{w} / \mathrm{v})$ sucrose in PBS, the fixed embryos were embedded in OCT compound (Sakura) and frozen. Transverse sections were prepared by cutting frozen brain with a cryostat (CM3050S; Leica) at a thickness of $20 \mu \mathrm{m}$ and mount on a glass slides (SuperFrost Plus; Fisher Scientific). Slides were washed in TBS-T $(0.1 \%$ Tween 20), then incubated in $2 \%$ donkey serum in TBS-T (blocking solution) for $30 \mathrm{~min}$ at room temperature. Slides were further incubated with primary antibodies diluted in blocking solution for overnight at $4^{\circ} \mathrm{C}$. The slides were washed three times for $10 \mathrm{~min}$ each in TBS-T, and then incubated for $1 \mathrm{~h}$ with secondary antibodies diluted in blocking solution at room temperature, washed again, and mounted using Fluoromount G (Southern Biotech). Images were taken using a Zeiss LSM 510 confocal microscope.

Open-book preparation and DiI axon labeling. Mouse E11.5 spinal cord open-books were prepared as described previously (Zou et al., 2000; Lyuksyutova et al., 2003; Shafer et al., 2011). Mouse spinal cord openbooks were immediately fixed with $4 \%$ PFA. To visualize anteriorposterior projection of commissural axon, DiI labeling was used in the open-book preparation. DiI injection and quantification were completed as described previously (Zou et al., 2000; Lyuksyutova et al., 2003; Wolf et al., 2008; Shafer et al., 2011). The number of injection sites and embryos are indicated in Figure 5D.

Statistical analysis. Statistical analysis for multiple comparison was performed using one-way ANOVA followed by a Bonferroni post hoc test for multiple comparisons. To compare two groups, Student's $t$ test was used (two-tailed distribution). To compare Frizzled3/AP-2 colocalization or filopodia number between in the proximal and distal side (see Fig. $8 C, D)$, we used Wilcoxon signed-rank test. We used one-way ANOVA followed by Bonferroni post hoc test when we compared colocalization or filopodia number between BSA in the proximal and Wnt5a proximal side (or between BSA distal and Wnt5a distal side).

\section{Results}

Frizzled 3 is colocalized with AP-2 complexes at the tip of filopodia in commissural axon growth cones

Clathrin and AP-2-mediated endocytosis of Frizzled is a critical step for PCP signaling (Yu et al., 2007; Sato et al., 2010). We previously proposed that Vangl2, which is enriched on the tips of growing filopodia, promotes Frizzled3 endocytosis (Shafer et al., 2011). Here, we directly tested whether Frizzled 3 can be endocytosed at the tip of filopodia in the growth cones. WT mouse E11.5 embryos were dissected and dorsal spinal commissural neurons were dissociated and cultured for $2 \mathrm{~d}$. Commissural neurons were then stimulated with Wnt5a and stained with anti-Frizzled 3 antibodies and anti- $\alpha$-Adaptin antibodies to detect endogenous Frizzled 3 and AP-2 complex (Fig. 1A). We found that endogenous AP-2 complexes can be observed at the tip of filopodia. Moreover, Wnt5a enhanced Frizzled 3 colocalization with AP-2 at filopodia tips (Fig. 1 $A, B$ ). Wnt5a treatment did not change total filopodia number during the time frame of our observation (5 min; Fig. 1C). We also tested whether Frizzled 3 can interact with other components of endocytic machinery. We prepared GST-fused mouse Frizzled3 cytoplasmic tail (GSTFzd3cyto; 505-666 aa; Fig. 1D) and performed GST-pulldown assay using mouse P14 whole-brain extract. $\alpha$-Adaptin was precipitated with GST-Fzd3cyto but not GST protein only (Fig. 1D). This is consistent with Frizzled3 being colocalized with $\alpha$-Adaptin. Moreover, AP180 and Amphiphysin, which bind to AP-2 and regulate clathrin and AP-2-mediated endocytosis, were also precipitated with GST-Fzd3cyto. Because we used the C-terminal domain of Frizzled3, which does not include Dishevelled binding region, our results suggest that Frizzled3 interacts with endocytic machinery directly rather than through Dishevelleds (Fig. 1E). Furthermore, we found that 5 min of Wnt5a treatment did not affect EphB1 and AP-2 colocalization at the tip of filopodia (Fig. $1 F, G$ ). This result suggests that Wnt5a effect is specific to Frizzled3. Together, these results suggest that Frizzled 3 can be endocytosed at the tips of filopodia and Wnt5a promotes Frizzled 3 endocytosis at the tips.

\section{Frizzled 3 undergoes endocytosis via the tips of filopodia}

We then tracked Frizzled 3 using a double-labeling construct (Fig. $2 A$ ). Frizzled 3 was tagged with tdTomato to the carboxyl domain and the FLAG epitope tag was engineered to the extracellular N terminus. First, we tested whether this Flag-Frizzled3-tdTomato can still transduce Wnt-PCP signaling. We found that in HEK293 cells expressing Flag-Frizzled3-tdTomato, Wnt5a increased the level of phosphorylated c-Jun, suggesting that Flag-Frizzled3tdTomato are functional (Fig. 2B). Plasma membrane-localized Frizzled 3 was pulse labeled by anti-FLAG antibodies conjugated with Alexa Fluor 488. We then performed time-lapse imaging in the commissural axonal growth cones using Spinning Disk Confocal microscopy (Fig. $2 E-G$ ). The yellow Frizzled 3 vesicles represent the cell-surface Frizzled 3 when the cells were pulse labeled with anti-FLAG antibodies. The red Frizzled 3 vesicles are nascent Frizzled 3 pools, which were not on the cell surface when the anti-FLAG antibodies were added briefly.

We found that yellow Frizzled 3 vesicles continuously emerged from the tips of growth cone filopodia and they moved inward along the filopodia (Fig. 2F, G, Row 1-4). These new yellow vesicles contain the FLAG antibody labeled Frizzled3 protein newly endocytosed. Some of the vesicles moved all the way into the central domain of the growth cone. Some yellow Frizzled3 vesicles were transported out to the tip of filopodia and then disappeared. It is likely that these vesicles exocytosed on the tips and then the fusion protein immediately diffused in the plasma membrane (Fig. $2 F, G$, Row 1-4; dash-line boxes indicate the position of high-magnification images). We also made a similar construct using a mutant Frizzled3 (7A) with all seven phosphorylation 


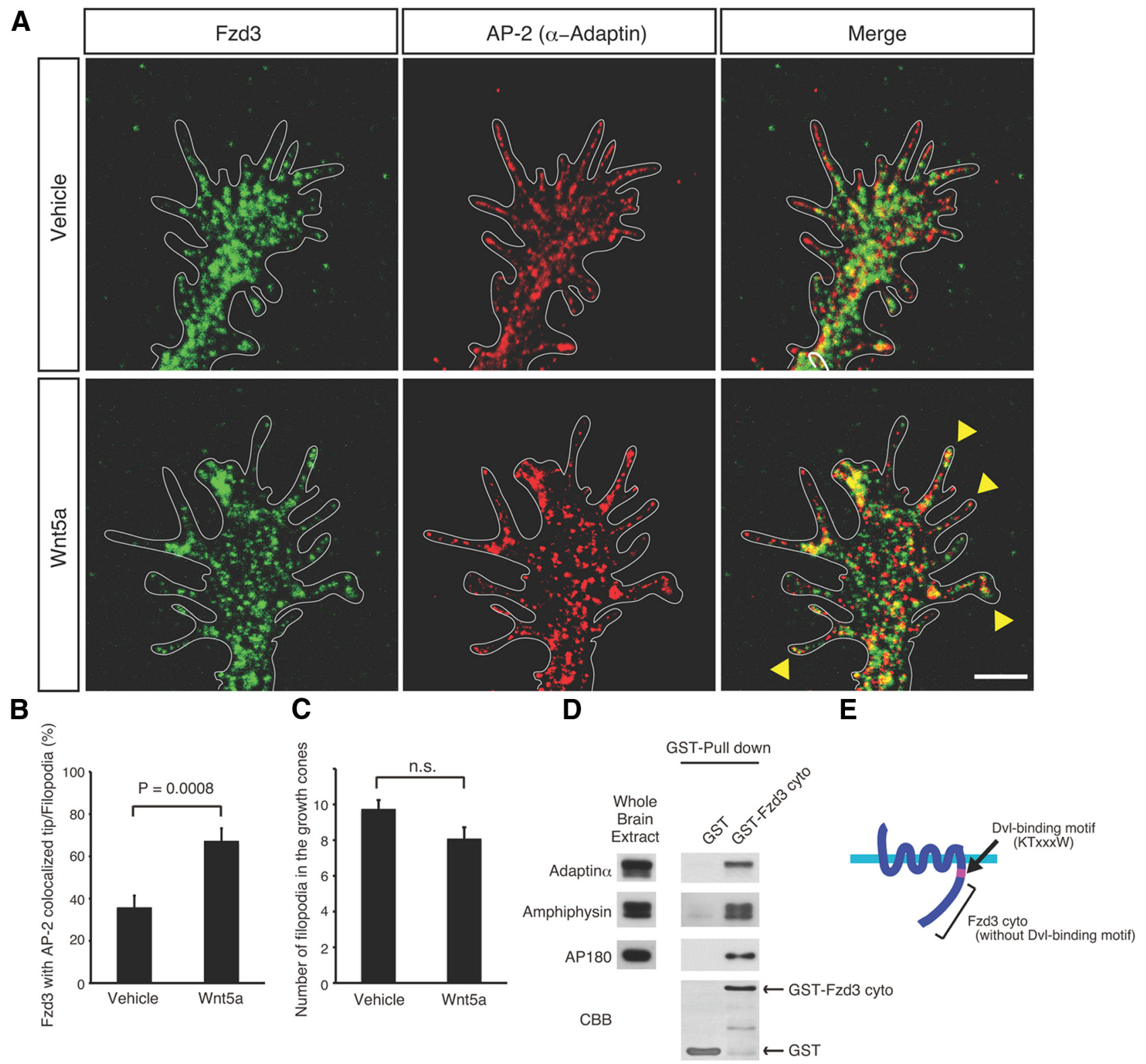

$\mathbf{F}$
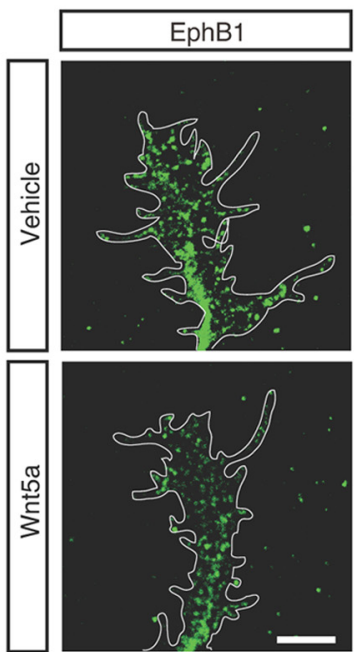
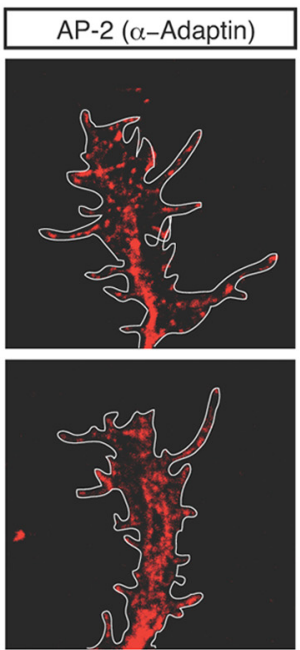
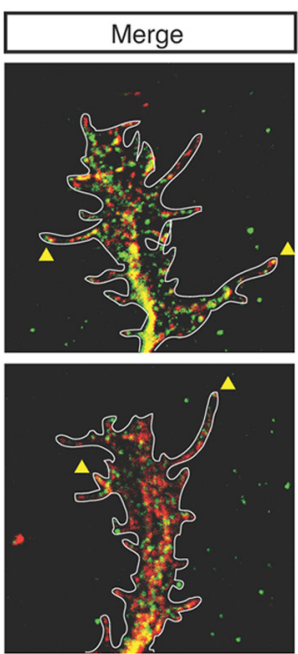

$\mathbf{G}$

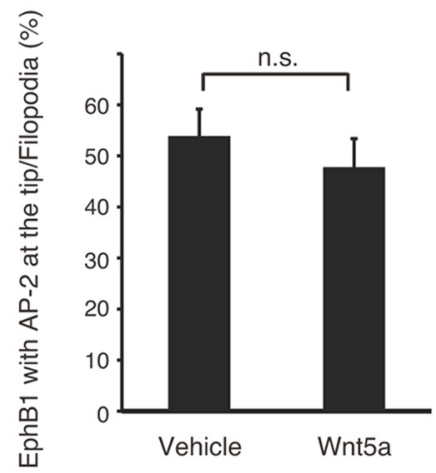

Figure 1. Frizzled 3 is colocalized with AP-2 complexes at the tip of filopodia in the commissural axon growth cones. $A$, Immunostaining of endogenous Frizzled 3 and $\alpha$-Adaptin in the dissociated commissural axon growth cones. Endogenous Frizzled 3 is colocalized with $\alpha$-Adaptin at the tip of filopodia in Wnt5a-dependent manner. Scale bar, $5 \mu \mathrm{m}$. B, Quantification of the colocalization of Frizzled 3 and AP-2 complexes at the tips of filopodia in $\boldsymbol{A}$. The percentage of filopodia with colocalized Frizzled and AP-2 puncta. Data are the mean \pm SEM. C, (Figure legend continues.) 
sites (induced by Dishevelled1) mutated (Shafer et al., 2011). We routinely observed yellow mutant Frizzled3 (7A) vesicles, which moved back along the filopodia, suggesting that Frizzled 3 endocytosis does not require hyperphosphorylation. On the other hand, once they have moved to the tips of filopodia, mutant Frizzled 3 (7A) vesicles stayed at the tip of filopodia for a much longer time (Fig. 2D). This suggests that Frizzled3 phosphorylation is required for its efficient exocytosis. Consistent with this, FLAG signal intensity of Frizzled3 (7A) mutant is less than that of Frizzled 3 WT, indicating that 7A mutation impairs Frizzled 3 exocytosis (Fig. 2C; data are normalized by WT, 7A $=0.59 \pm 0.10$ ).

\section{Wnt5a promotes endocytosis of Frizzled 3 vesicles from filopodia tips}

Using this new construct, we set out to test the behavior of Frizzled3 vesicles when PCP signaling is activated by Wnt5a, focusing on the tips of filopodia (Fig. $2 F-I$ ). We first characterized vesicle movement relative to the filopodia membrane, which may undergo elongation or shrinking. Some filopodia shrank very fast (within 2 frames/6 s), making it impossible to track vesicles inside. Therefore, we excluded those fast shrinking ones and only measured vesicle movement in slowly shrinking filopodia (at least 20-30 s). We also excluded overlapped filopodia, which are also often seen during imaging and would confuse the quantification. As shown in Figure 2, $F$ and $G$, high-magnification columns, Frizzled3 vesicles move much faster than filopodia movement. Therefore, these vesicle movement reflect their trafficking within the filopodia, not the movement of the growing/shrinking of filopodia per se.

We then analyzed time-lapse imaging and found that Wnt5a addition $(100 \mathrm{ng} / \mathrm{ml})$ increased the number of Frizzled 3 vesicles appearing from the tips and moving inward, away from the tips, in commissural axon growth cones, which correlates with elongation of filopodia, not the shrinking filopodia. In the absence of Wnt5a, the rate of outward movement/10 s was $0.33 \pm 0.03$ and inward movement/10 s was $0.89 \pm 0.05$ in growing filopodia, whereas in shrinking filopodia, outward movement/10 s was $0.78 \pm 0.08$ and inward movement $/ 10 \mathrm{~s}=0.46 \pm 0.07$ (Fig. $2 \mathrm{H}$ ). In the presence of Wnt5a, outward movement/10 s was $0.29 \pm$ 0.06 and inward movement/10 s was $1.07 \pm 0.06$ in growing filopodia, whereas in shrinking filopodia, outward movement/10 $\mathrm{s}$ was $0.81 \pm 0.11$ and inward movement/10 s was $0.44 \pm 0.06$ (Fig. $2 \mathrm{H}$ ). Mutant Frizzled3 (7A), which cannot be hyperphosphorylated, on the other hand, does not respond to Wnt5a (Fig. $2 I$ ). These results suggest that Wnt5a promotes Frizzled 3 endocytosis from filopodia tips of commissural growth cones.

\section{Antagonistic interactions between Dishevelled 2 and Dishevelled1 in Frizzle3 phosphorylation and trafficking}

While testing the roles of all three Dishevelleds in regulating Frizzled3 phosphorylation, we uncovered an unexpected difference among the three Dishevelleds. In our previous study, we showed that Frizzled3 hyperphosphorylation, induced

\footnotetext{
$\leftarrow$

(Figure legend continued.) Quantification of the number of filopodia in $\boldsymbol{A}$. Data are the mean \pm SEM. $\boldsymbol{D}$, Frizzled 3 cytoplasmic region binds to a subset of endocytosis-related proteins. $\alpha$-Adaptin, Amphiphysin, and AP180 are coprecipitated with GST-Fzd3cyto, but not GST control. E, The schematic diagram of GST-Fzd3cyto. GST-Fzd3cyto does not contain the Dishevelled binding motif (KTxxW). $\boldsymbol{F}$, Immunostaining of endogenous EphB1 and $\alpha$-Adaptin in the dissociated commissural axonal growth cones. $\mathbf{G}$, Endogenous EphB1 is also colocalized with $\alpha$-Adaptin at the tip of filopodia, although Wnt5a does not affect colocalization there. Scale bar, $5 \mu \mathrm{m}$.
}

by Dishevelled1, causes a mobility shift (Shafer et al., 2011). We found that, while Dishevelled3 also induces Frizzlzed3 hyperphosphorylation, Dishevelled2 does not (Fig. 3A). Consistent with this, we also found that Dishevelled 1 and Dishevelled3 increase Frizzlzed3 cell-surface accumulation, but not Dishevelled2 (Fig. 3A). Furthermore, Dishevelled2 suppressed Dishevelled1-induced Frizzlzed3 hyperphosphorylation (Fig. 3B).

Frizzled3 hyperphosphorylation results in its cell-surface accumulation and inactivation of PCP signaling (Shafer et al., 2011). Therefore we hypothesized that Dishevelled2, but not Dishevelled1, mediates noncanonical Wnt signaling, such as PCP signaling. To address this, we developed the specific shRNA constructs against Dishevelled1 and Dishevelled2. We found that knockdown of Dishevelled2 suppressed Wnt5a-induced JNK activation (Fig. 3C). On the other hand, JNK was still activated in the Dishevelled1 knockdown cells (Fig. 3C). These results suggest that Dishevelled2 is necessary for Wnt-PCP signaling, whereas Dishevelled1 inhibits it.

\section{aPKC inhibits Dishevelled1-induced Frizzled 3 hyperphosphorylation}

Our previous study showed that the localization and activity of Frizzled 3 is regulated by its phosphorylation and aPKC is required for Wnt-mediated axon attraction and guidance (Wolf et al., 2008; Shafer et al., 2011). To investigate the interaction of aPKC and Frizzled 3 trafficking, we tested the role of aPKC and found that constitutively active aPKC inhibits Dishevelled1induced Frizzled3 hyperphosphorylation (Fig. 4A). PAR6 is a protein that forms a complex with aPKC in A-BP signaling. PAR6 and aPKC cooperatively inhibit Dishevelled1-induced Frizzled3 hyperphosphorylation (Fig. 4B).

We then investigated the interactions between aPKC and the Dishevelleds. The phosphorylation of T410 of PKC $\zeta$ causes the activation of this kinase. We found that Dishevelled2, not Dishevelled1, increased T410 phosphorylation in dissociated primary dorsal spinal cord neurons, suggesting that only Dishevelled 2 activates aPKC (Fig. $4 C$ ). In these cultures, Wnt5a treatment increased T410 phosphorylation of aPKC as well as phosphorylated JNK (indicating JNK activation; Fig. 4D). These results suggest that Wnt5a-Dishevelled2 signaling indeed activates aPKC, which, in turn, inhibits Dishevelled1induced Frizzled3 hyperphosphorylation.

\section{Increased Frizzled 3 hyperphosphorylation in Celsr3 knock-out mice}

To test whether Frizzled3 phosphorylation is important in PCP signaling in vivo, we investigated Frizzled 3 phosphorylation state in Ceslr3 knock-out mice (Tissir et al., 2005). Ceslr3 is a homolog of Drosophila flamingo and encodes an essential component of PCP pathway in many contexts. We found, in whole-brain and spinal cord extracts from E11.5 Celsr3 knock-out embryos, the upper band of Frizzled3 (hyperphosphorylated Frizzled3) was increased (Fig. $5 A, B$ ). Consistent with this, phosphorylation of JNK is diminished in both brain and spinal cord extracts from Celsr3 knock-out mouse. This result indicates that Frizzled3 phosphorylation is an important regulatory mechanism for PCP signaling in vivo.

\section{PCP signaling is required in commissural neurons for their proper anterior-posterior guidance}

PCP components are expressed in commissural axon growth cones and Frizzled 3 and Celsr 3 knock-out mice, as well as a 
A

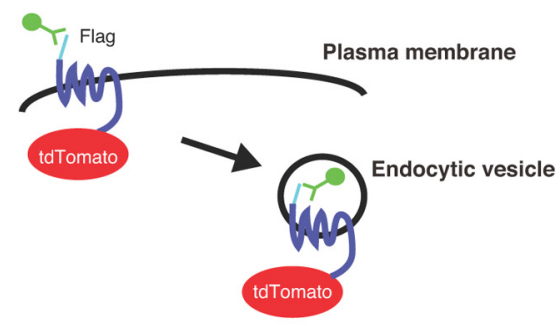

B

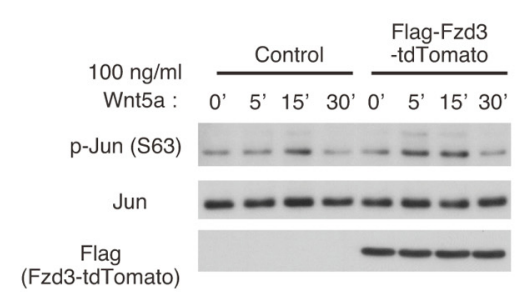

E
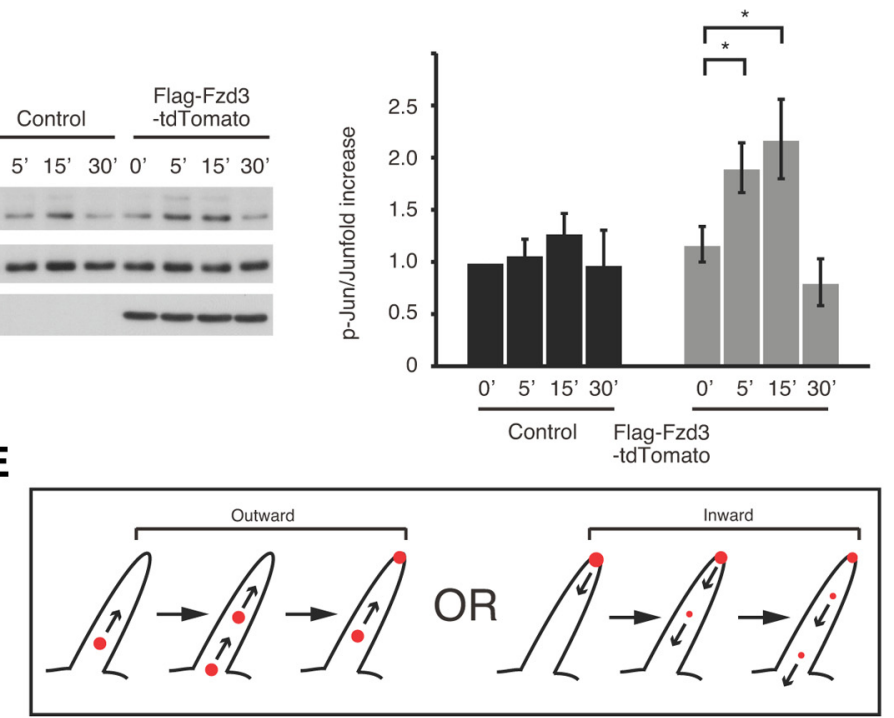

C

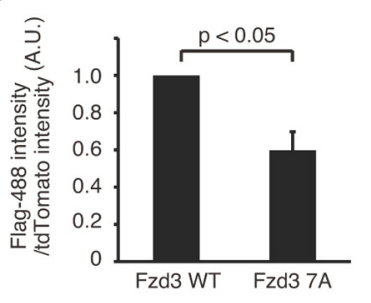

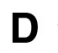

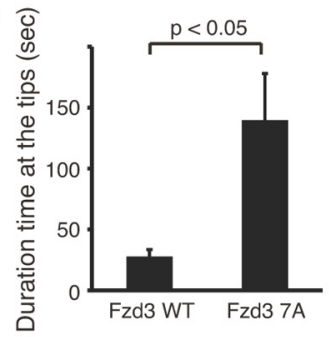

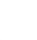
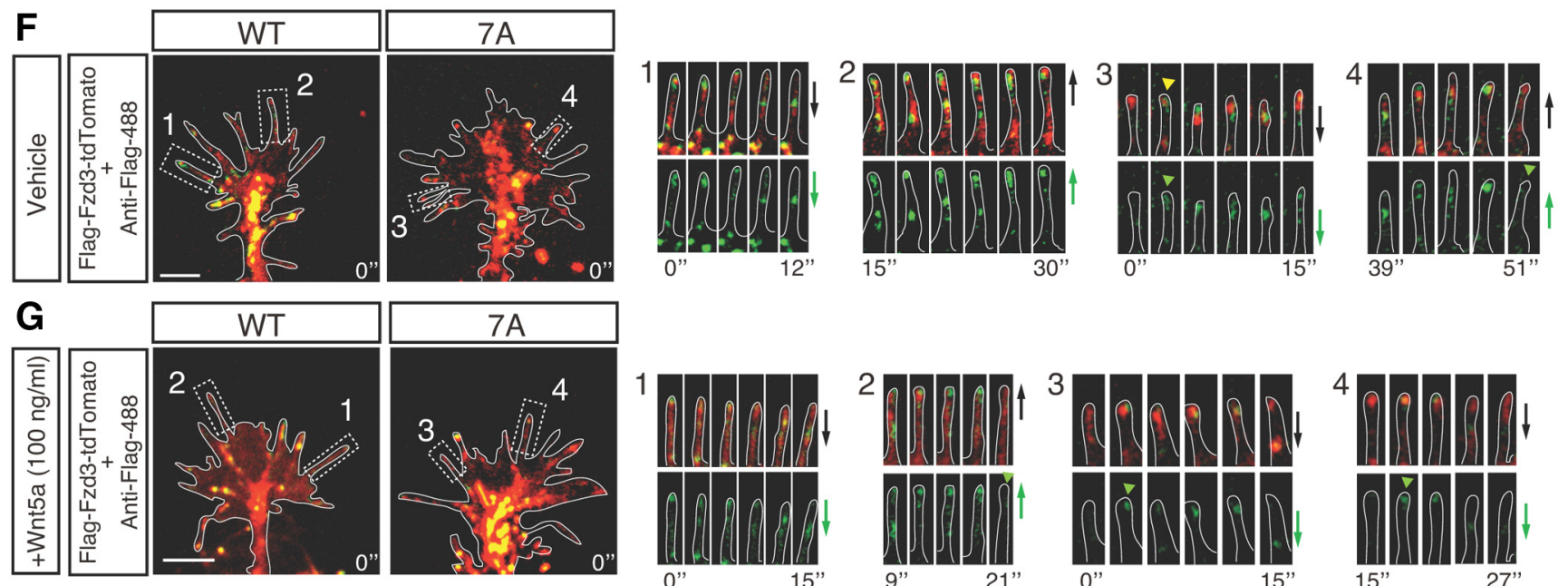

H
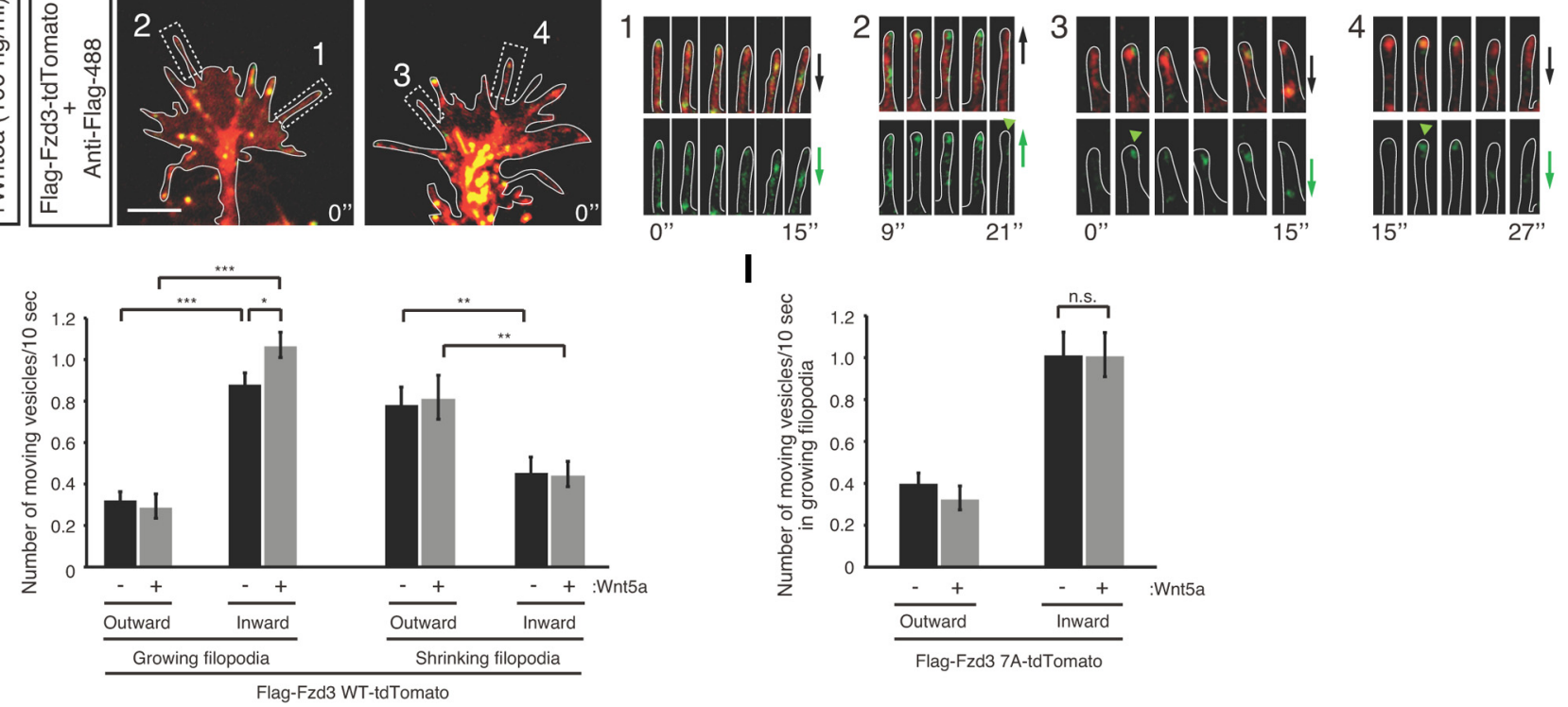

I

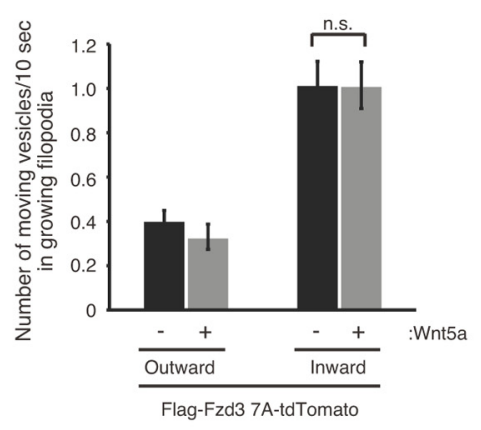

Figure 2. Frizzled3 undergoes endocytosis via the filopodia tips of commissural axon growth cones. $\boldsymbol{A}$, Schematic diagram of a double labeling construct for Frizzled3. B, Flag-Frizzled3-tdTomato construct can mediate Wnt5a activation of JNK. Quantification data are the mean \pm SD of values. ${ }^{*} p<0.05$. C, Quantification of FLAG signal intensity normalized by total Frizzled3 expression level (intensity of tdTomato; $15 \mathrm{~min}$ at $37^{\circ} \mathrm{C}$ ). Data are the mean $\pm S D$. D, Quantification of the duration time of Frizzled $3 \mathrm{WT}$ and $7 \mathrm{~A}$ mutant at the tip of filopodia. Frizzled $37 \mathrm{~A} \mathrm{mutant} \mathrm{stays} \mathrm{longer} \mathrm{at} \mathrm{the}$ tips than WT. Data are mean \pm SD. $\boldsymbol{E}$, Diagram for method of quantification of vesicle movement. $\boldsymbol{F}$, Time-lapse imaging of FLAG-Frizzled3 WT and 7A mutant-tdTomato in the commissural axon growth cones in the absence of Wnt5a. Dash-line boxes indicate the position of high-magnification images. Yellow (green + red) vesicles represent "once" plasma membrane-localized, and currently internalized Frizzled3. Once internalized, some Frizzled3 WT is again transported back to the tips of filopodia, suggesting Frizzled3 WT is recycled. Row 1, inward movement; Row 2, outward movement; Row3, Frizzled3 appeared at the tip and move inward; and Row 4, Frizzled3 move outward and disappeared at the tip. Scale bar, $5 \mu \mathrm{m}$. G, Time-lapse imaging of FLAG-Frizzled3 WT and 7 A mutant-tdTomato in the commissural axonal growth cones in the presence of Wnt5a (100 ng/ml). Row 1, inward movement; Row 2, Frizzled 3 move outward and disappeared at the tip; and Rows 3 and 4, Frizzled 3 appeared at the tip and move inward. Scale bar, $5 \mu \mathrm{m}$. $\boldsymbol{H}$, Quantification of the Frizzled 3 WT-vesicle movement in the growing and shrinking filopodia. Wnt5a increases the inward movement (from tips to central domain) of Frizzled 3 vesicles only in the growing filopodia. Data are the mean \pm SEM. ${ }^{*} p<0.05,{ }^{* *} p<0.005,{ }^{* * *} p<10^{-5} . I$, Quantification of the Frizzled3 (7A)-vesicle movement in the growing filopodia. Wnt5a does not change Frizzled3 (7A) vesicle movement. Data are the mean \pm SEM. 
A

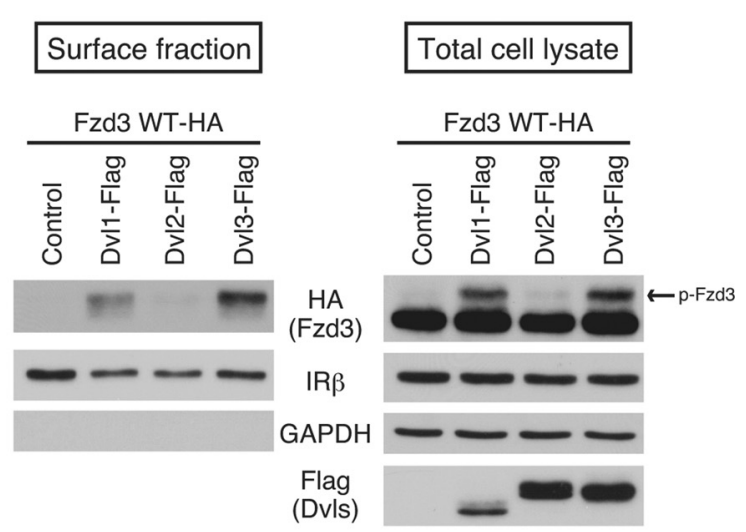

B

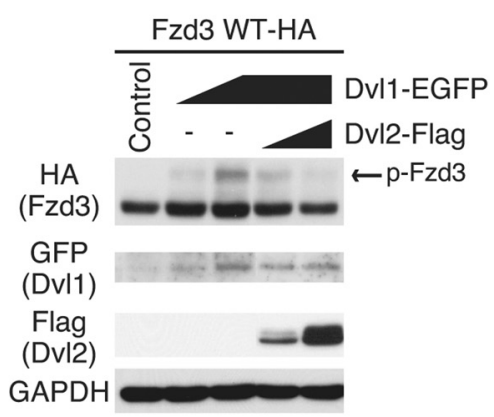

C

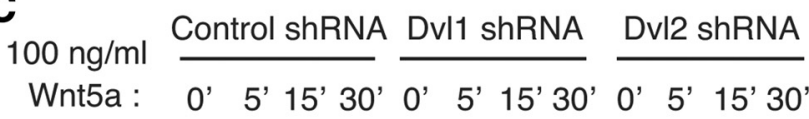
p-Jun (S63)

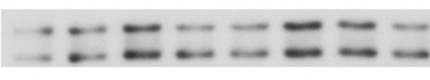

Jun

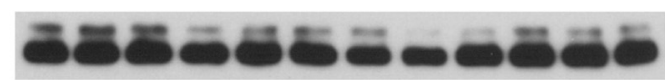

HA

(Fzd3)

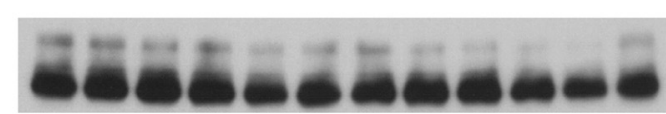

Dvl1

Dvl2
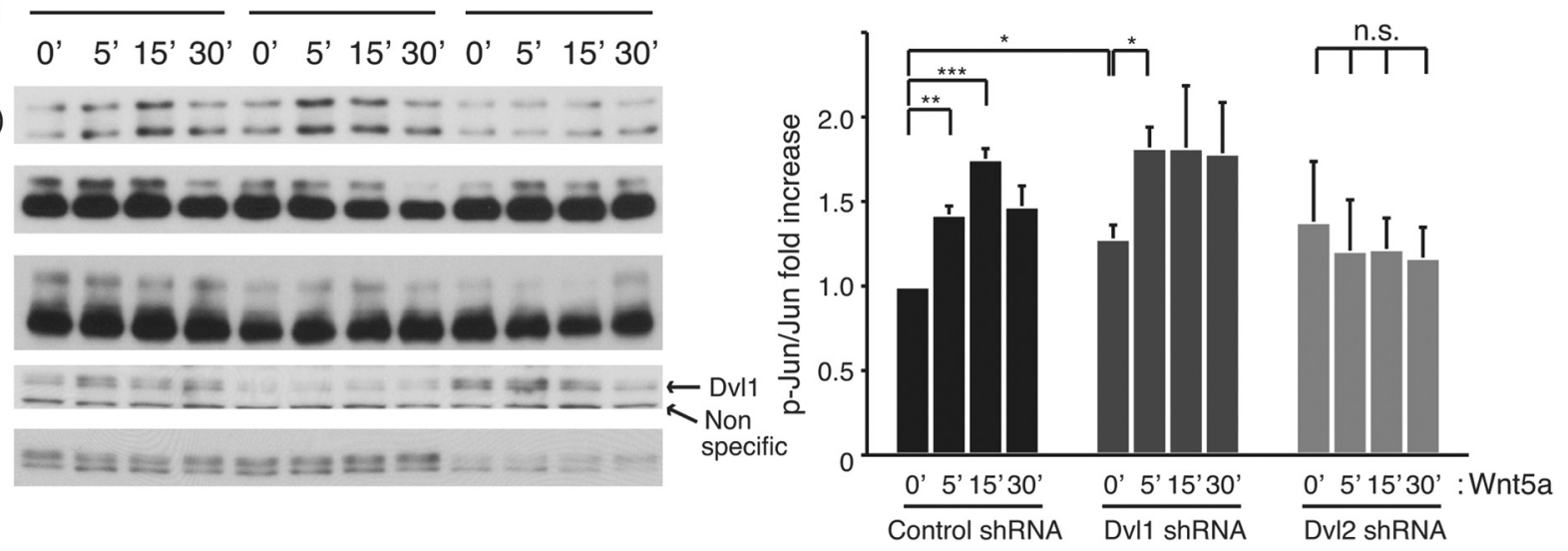

Figure 3. Dishevelled2 inhibits Dishevelled1-induced Frizzled3 hyperphosphorylation. $A$, Dishevelled1 and Dishevelled3 induce Frizzled3 cell-surface accumulation, but not Dishevelled2. GAPDH is used for cytoplasmic marker and IR $\beta$ (Insulin receptor $\beta$ ) is for cell-surface marker. B, Dishevelled2 inhibits Dishevelled1-induced Frizzled3 hyperphosphorylation (Dishevelled1:0.1 $\mu \mathrm{g}$ or $0.3 \mu \mathrm{g}$; Dishevelled2: $0.1 \mu \mathrm{g}$ or $0.3 \mu \mathrm{g}$ ). C, Dishevelled1 and Dishevelled2 have different roles in Wnt5a-induced JNK activation. Quantification data are the mean \pm SD of values. ${ }^{*} p<0.05$, ${ }^{* *} p<0.005$, ${ }^{* * *} p<0.0005$.

Vangl2 mutant mouse, looptail, display robust anterior-posterior guidance defects of spinal cord commissural axons (Lyuksyutova et al., 2003; Shafer et al., 2011; Fig. 5C). To directly test whether PCP signaling is required in commissural neurons but not the surrounding cells, such as the floor plate cells in the midline, we deleted Ceslr3 gene specifically in a subset of commissural axons using a Celsr3 conditional allele crossed into Wnt1-Cre (Charron et al., 2003; Matsumoto et al., 2007; Zhou et al., 2008). Wnt1-Cre is expressed in the dorsal-most margin of the spinal cord, where commissural neuron cell bodies are located, and the recombination mediated by Wnt1-Cre starts at E9.5 (Charron et al., 2003).

First, we tested whether the Celsr3 antibodies we generated recognize endogenous Celsr3 specifically. In contrast to WT, Ceslr3 staining is almost lost in the dissociated Celsr3 knock-out mouse commissural neurons (Fig. 5E), indicating that our Celsr3 antibodies recognize Celsr3 specifically. We then used these antibodies to verify the deletion of the Celsr3 gene in commissural neurons in Celsr $3^{\text {flox/flox }}$;Wnt1-Cre embryos. In E11.5 spinal cords of Celsr $3^{\text {flox/flox }}$ embryos, we found that Celsr3 is detected in the ventral and lateral funiculus, where postcrossing commissural axons grow (Fig. 5G, left). However, Celsr3 staining in the ventral and lateral funiculus is lost in Celsr $3^{\text {flox/flox }}$;Wnt1-Cre embryos (Fig. 5G, right).

We next examined the trajectory of commissural axons using $\mathrm{L} 1$ and TAG-1 staining (Fig. $5 D, F$ ). TAG-1 is expressed in the precrossing and crossing segments in the spinal cord, and L1 delineates postcrossing axons or growth cones. TAG-1 staining showed that the dorsoventral projection of precrossing commissural axons is normal in both Celsr $3^{\text {flox }}$ flox and Celsr $3^{\text {flox/flox }}$; Wnt1-Cre spinal cords. After crossing, the axons grew within the ventral and lateral funiculus in both genotypes, as shown by L1 staining (Fig. $5 F$ ). We then analyzed anterior-posterior guidance using DiI tracing and found severe anterior-posterior guidance defects in Celsr $3^{\text {flox/flox }}$; Wnt1-Cre embryos (Fig. $5 \mathrm{H}, \mathrm{I}$; Celsr $3^{\text {flox } /+}=85.7 \pm 13.9 \%$, Celsr $3^{\text {flox/flox }}=85.2 \pm 13.5 \%$, Celsr $3^{\text {flox/+ }} ;$ Wnt1-Cre $=$ $81.1 \pm 16.4 \%$, and Celsr3 ${ }^{\text {flox } / \text { flox }} ;$ Wnt $\left.1-C r e=16.9 \pm 4.5 \%\right)$. These results demonstrate that Celsr3 in the commissural neurons is important for the commissural axon anterior turning.

Arf6 is the small GTPase, which regulates Frizzled3 recycling To further investigate how Frizzled 3 trafficking is regulated and whether Frizzled3 recycling is necessary for axon guidance, we tested a number of Rabs and Arf6, which regulate the trafficking of many different kinds of receptor tyrosine kinases, G-proteincoupled receptors, and other types of cell-surface proteins (cadherins, integrins, etc.; Jackson and Casanova, 2000; Santy and Casanova, 2001). First, we performed coimmunoprecipitation experiments to investigate whether Rabs or Arf6 can interact with Frizzled3. We found that Frizzled 3 coimmunoprecipitated with Arf6-EGFP, but not with EGFP-Rab4, 5, 8, or 11 (Fig. 6A). Furthermore, Frizzled3 coimmunoprecipitated with Arf6 WT and T157A mutant, a fast cycling form and more active mutant than WT (Santy, 2002), more efficiently 
A

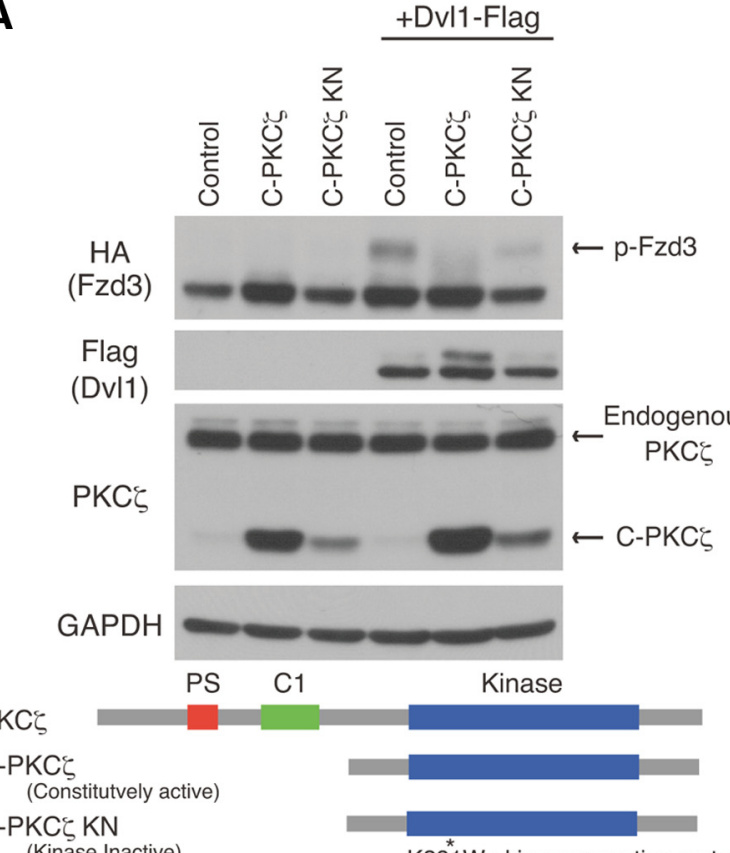

(Kinase Inactive)
B

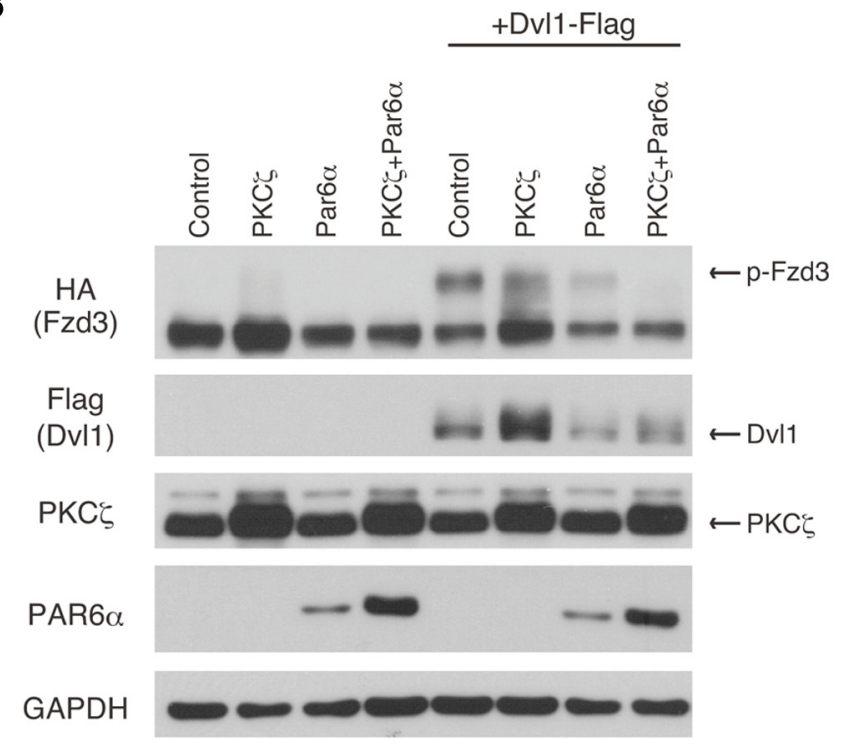

C

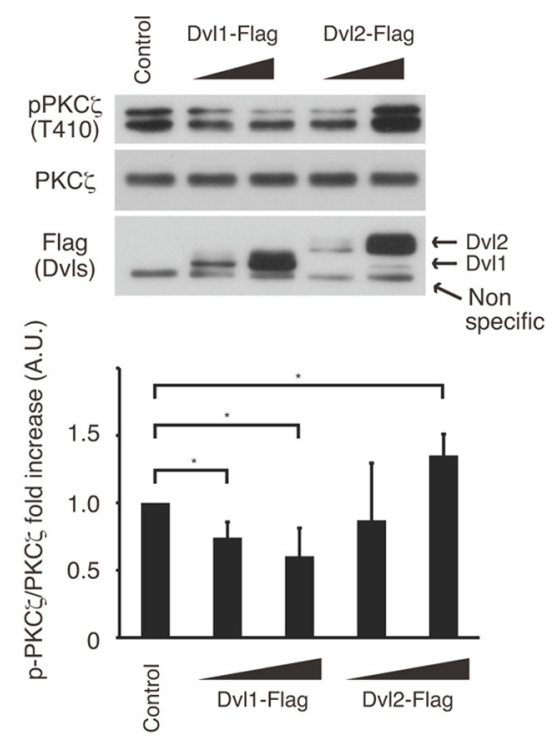

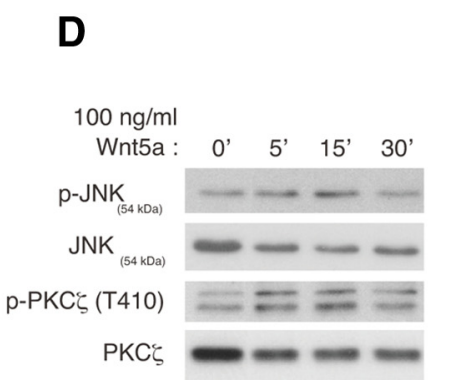
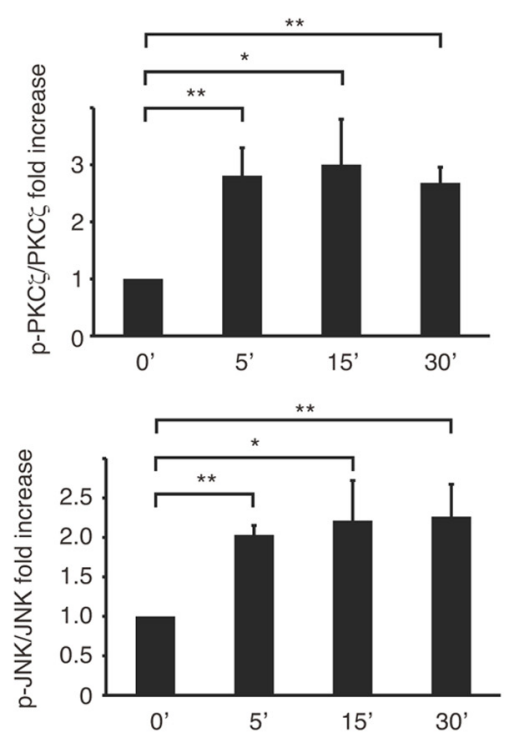

Figure 4. aPKC/PAR6, activated by Dishevelled2, inhibits hyperphosphorylation of Frizzled3 induced by Dishevelled1. $A$, Constitutively active aPKC inhibits Dishevelled1-induced Frizzled3 phosphorylation. B, PAR6 and aPKC cooperatively inhibit Dishevelled1-induced Frizzled3 phosphorylation. C, Dishevelled2, not Dishevelled1, activates aPKC (Dishevelled1: $0.1 \mu \mathrm{g}$ or $0.3 \mu \mathrm{g}$; Dishevelled2: $0.1 \mu \mathrm{g}$ or $0.3 \mu \mathrm{g}$ ). Quantification data are the mean \pm SD of values. ${ }^{*} p<0.05$. D, Wnt5a activates aPKC and JNK in commissural neurons. Quantification data are the mean \pm SD of values from three independent experiments; ${ }^{*} p<0.05,{ }^{* *} p<0.005$.

than with Arf6 T27N mutant, which can bind with only GDP and acts as a dominant-negative (Fig. 6B). We next investigated whether Frizzled3 phosphorylation affects the interaction between Arf6 and Frizzled3. We found that Arf6 was coimmunoprecipitated with 7A mutant, seven phosphorylation sites of which (induced by Dishevelled1) are mutated, more efficiently than with WT (Fig. 6C). This result suggests that Frizzled3 phosphorylation may inhibit the interaction between Arf6 and Frizzled 3 and thus inhibits its endocytosis.

To test whether Arf6 is involved in Frizzled3 trafficking, we analyzed the cell-surface level of Frizzled 3 by using the cellsurface biotinylation and avidin pull-down system. We found that Arf6 T157A constitutively-active mutant suppressed Dishevelled1- induced Frizzled 3 surface accumulation and hyperphosphorylation (Fig. 6D). Consistent with this, dominant-negative Arf6 (DN-Arf6; T27N mutant) expression significantly enhanced Frizzled3 cellsurface accumulation even without Dishevelled1 overexpression (Fig. 6E). These results suggest that Arf6 regulates Frizzled3 recycling. We also noticed a lower band in the left (control) lane. Therefore, we performed phosphatase assay using surface fraction. The upper band in surface fraction was completely removed by phosphatase treatment (Fig. $6 F$ ). Interestingly, this lower Frizzled3 band, which is higher than the lowest band in the total extract, is still there, suggesting that the lower band in the surface fraction represents other modification (Fig. $6 F$ ). Because it has been reported that Frizzled7 and 8 are glycosylated (Yamamoto et 
A

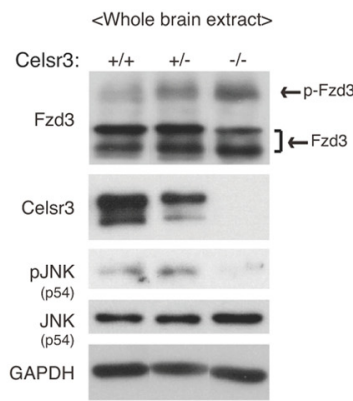

C

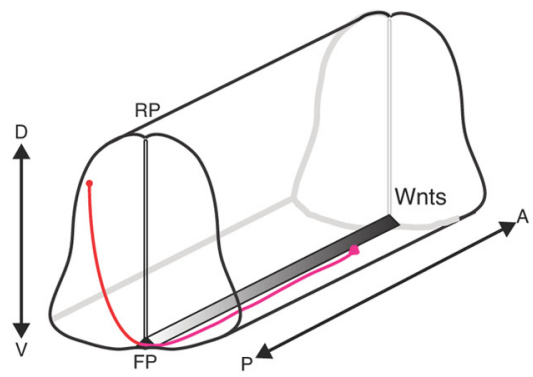

E

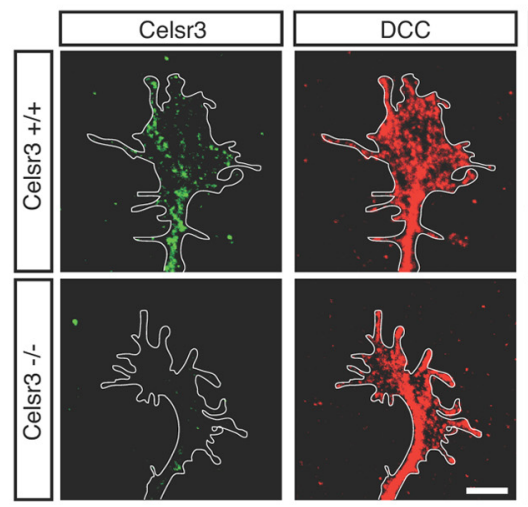

$<$ Whole spinal cord extract>

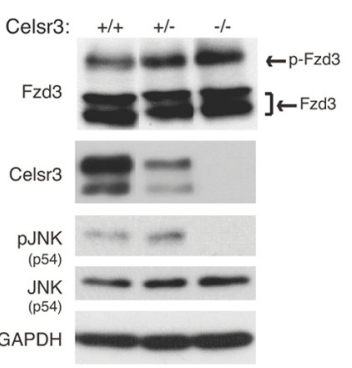

B

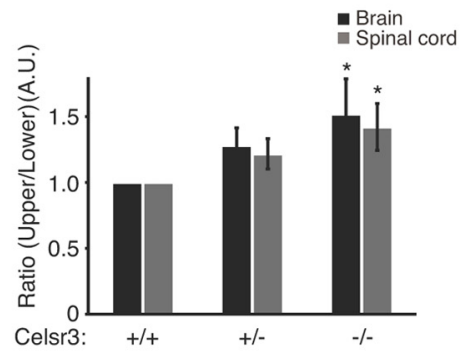

D
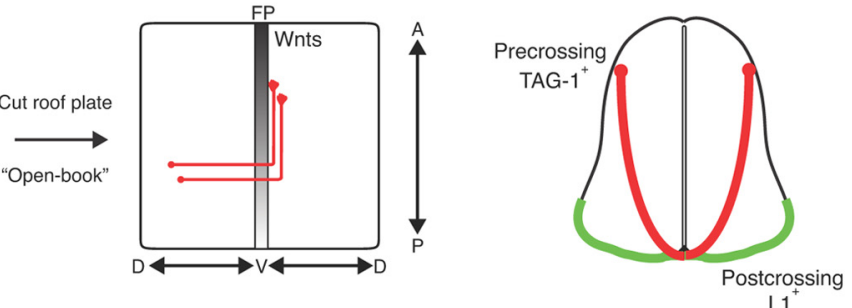

$\mathrm{L}^{+}$

G
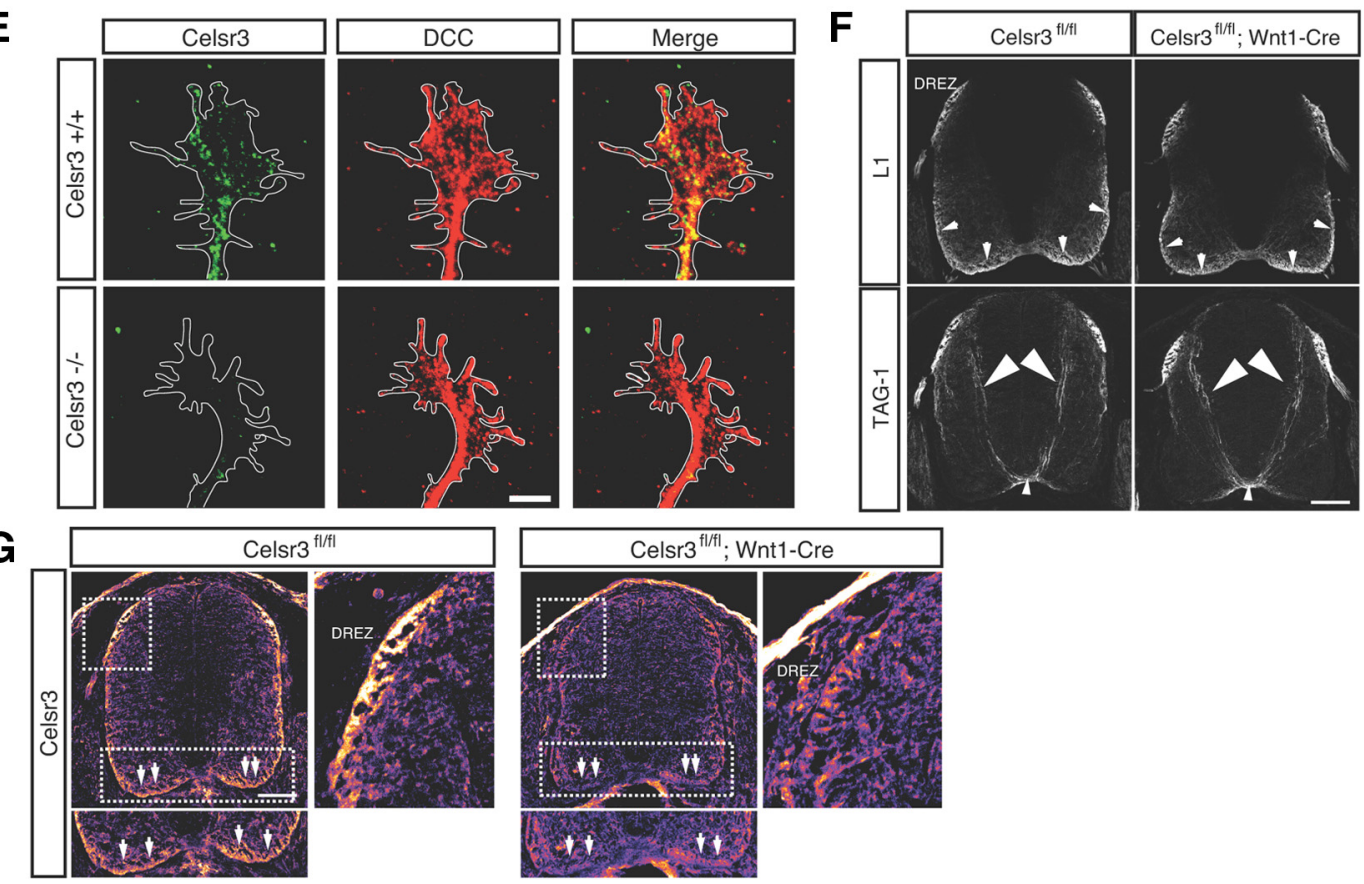

H
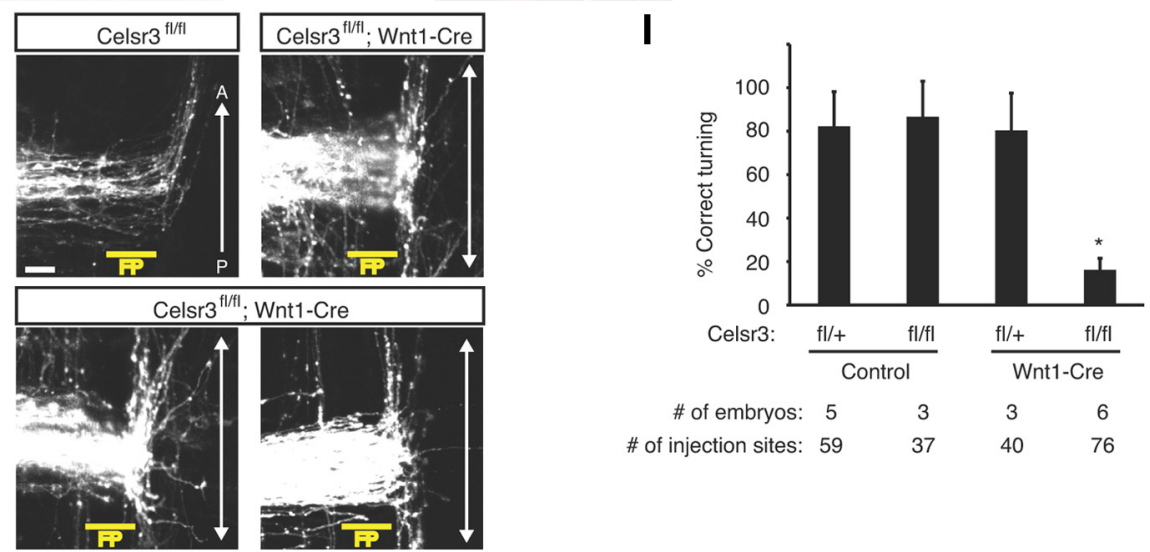

\# of embryos: $5 \quad 3 \quad 3 \quad 3 \quad 6$

\# of injection sites: $59 \quad 37 \quad 40 \quad 76$

Figure 5. Increased Frizzled 3 hyperphosphorylation in Celsr 3 knock-out mice and requirement of Ceslr3 in commissural neurons. $A$, Increase of Frizzled 3 hyperphosphorylation in Celsr3 knock-out mouse (E11.5). B, Quantification of the ratio between phosphorylated Frizzled3 and nonphosphorylated Frizzled3 in Celsr3 knock-out mice brain and spinal cord tissue lysate. Intensities of upper bands are divided by that of lower bands and normalized by WT $(+/+)$. The number of $+1+$ embryos $=9,+1-=6,-1-=5$ from three different litters. (Figure legend continues.) 
al., 2005), this Frizzled3 mobility shift might also be due to glycosylation. Therefore we tested this possibility and found that PNGase F, an amidase that cleaves $N$-linked glycans from glycoproteins, further fastened both higher and lower Frizzled 3 bands, suggesting that all Frizzled 3 on the plasma membrane are glycosylated and some of them are phosphorylated. Importantly, constitutively active and WT Arf6 greatly also increases Frizzled3 mobility on the gel (Fig. 6D). They increased the lowest band, which appears to correspond to the unmodified Frizzled3, suggesting that Arf6 might regulate not only phosphorylation but also glycosylation.

Because Frizzled endocytosis is required for Wnt-induced PCP signal activation (Yu et al., 2007; Sato et al., 2010), we tested whether Arf6 is involved in Wnt-PCP signaling. In control cells, Wnt5a treatment increased phosphorylation of c-Jun. However, in DN-Arf6-expressing cells, Wnt5a treatment did not increase, but rather decreased the phosphorylation of c-Jun very rapidly, suggesting that Arf6 activity is required for Wnt5a-induced PCP signal activation (Fig. 6G). These data suggest that Arf6 mediates Frizzled 3 endocytosis and PCP signaling.

\section{Arf6 is required for Wnt-mediated commissural axon outgrowth}

We previously showed that Wnt5a promotes commissural axon elongation via PCP signaling (Shafer et al., 2011). Therefore, we tested whether Arf6 is involved in Wnt5a-induced commissural axon elongation. In control shRNA-expressing neurons, Wnt5a treatment significantly promoted commissural axon outgrowth. On the other hand, Arf6 knockdown abolished Wnt5a-induced commissural axon outgrowth (Fig. $7 A, B$; data are normalized by Control shRNA, Control shRNA + Wnt5a $=1.43 \pm 0.03$, Arf6 shRNA $=1.33 \pm 0.06$, and Arf6 shRNA + Wnt5a $=$ $1.06 \pm 0.11)$. We validated the knockdown efficiency of shRNA targeting rat Arf6 by using expression plasmid encoding rat Arf6-EGFP (Fig. 7C).

After analyzing Arf6 trafficking in the growth cones, we found that, like Frizzled3, Arf6-EGFP vesicles are also present at the tips of growth cone filopodia (Fig. 7D, left and box1). Moreover, the small Arf6-EGFP-positive vesicles also appear from the tips and move inward along filopodia (Fig. 7D). Importantly, inward

\footnotetext{
$\leftarrow$

(Figure legend continued.) $\quad{ }^{*} p<0.05$. C, A schematics of commissural axon pathfinding in mouse E11.5 or rat E13 spinal cords. Spinal cords are dissected and splayed open from the roof plate to give rise to open-book preparation allowing the visualization of commissural axons pathfinding before, during and after midline crossing of the spinal cords are prepared. D, Schematics of an mouse E11.5 or rat E13 spinal cord transverse section. Spinal cord is bilaterally symmetrical at this stage and there are commissural neurons and their axons on both sides of the midline. Green is the TAG-1-positive precrossing segment approaching the ventral midline, and red indicates the L1-positive postcrossing axon segment after midline crossing. $\boldsymbol{E}$, AntiCelsr3 antibodies recognize Celsr3 specifically. Scale bar, $5 \mu \mathrm{m}$. F, TAG1 immunostaining shows normal dorsoventral trajectory in both genotypes, and $\mathrm{L} 1$ immunostaining shows commissural axons can grow within the ventral and lateral funiculus in both genotypes. Scale bar, $100 \mu \mathrm{m}$. $\mathbf{G}$, Celsr3 is expressed in postcrossing commissural axons. Transverse sections of E11.5 spinal

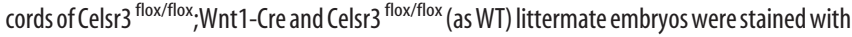
anti-Celsr3 antibodies. The images are pseudocolored heat map of Celsr3 immunostainings. Dash-line boxes indicate the position of high-magnification images. Arrows indicate postcrossing segments. Scale bar, $100 \mu \mathrm{m}$. $\boldsymbol{H}$, Anterior-posterior guidance defects in Celsr $3^{\text {flox/flox, }}$; Wnt1-Cre embryos. Commissural axons were labeled by lipophilic Dil injection into the "open-

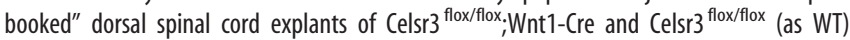
littermate embryos. Scale bars: $50 \mu \mathrm{m}$. I, Quantification of open-book assay experiments in $C$. The graph represents the frequency of the anterior turning (correct turning) as a percentage of all injection sites. ${ }^{*} p=0.00001$ compared with other three genotypes. $D$, dorsal; $V$, ventral; $A$, anterior; $\mathrm{P}$, posterior; $\mathrm{RP}$, roof plate; $\mathrm{FP}$, floor plate; DREZ, dorsal root entry zone.
}

movement of Arf6-EGFP vesicles is observed much more frequently in growing filopodia, but not as frequently in shrinking filopodia (Fig. 7D, right graph). This result suggests that Frizzled3 recycling mediated by Arf6 does initiate more frequently in extending/growing filopodia than in shrinking ones.

Based on our results, we hypothesize that Dishevelled1 inhibits Wnt/PCP signaling by keeping Frizzled3 in a hyperphosphorylated state and on plasma membrane (Fig. 7, left). PCP signaling can be activated by Wnts and the activated Dishevelled 2 can remove inhibition of PCP signaling by activating aPKC, which inhibits Dishevelled1, thus causing signal amplification. And Arf6 is required for Frizzled3 endocytosis once PCP signaling is activated (Fig. $7 F$, right).

\section{Frizzled 3 is endocytosed asymmetrically in Wnt5a gradient}

To test whether the tightly regulated Frizzled 3 endocytosis mediates growth cone turning, we exposed commissural axon growth cones to a Wnt5a gradient using the Dunn chamber (Yam et al., 2009). Commissural neurons were grown in culture and then exposed to a gradient of Wnt5a. We tested our system and found that it takes $\sim 20 \mathrm{~min}$ to form the gradient from end to end using $40 \mathrm{kDa}$ tetramethylrhodamine dextran (data not shown). Thirty minutes after the addition of Wnt5a or BSA (as a control), commissural neurons were fixed. Thus, these growth cones would have been in a stable gradient for $\sim 10 \mathrm{~min}$. We then immunostained these growth cones with Frizzled 3 and $\alpha$-Adaptin, a subunit of AP-2 complex. In control BSA gradient, Frizzled 3 and AP-2 colocalized tips were equally distributed in both proximal and distal side (Fig. $8 A-C$ ), suggesting that Frizzled 3 is endocytosed randomly at the filopodia tips in the absence of Wnts gradient. In contrast, there was a significant bias for a proximal (closer to Wnt5a source) distribution of Frizzled3 and AP-2 colocalized tips. (Fig. $8 A-C$ ). In this time frame of our experiments, Wnt5a gradient did not affect filopodia formation in both proximal and distal side (Fig. 8D). This result suggests that Frizzled 3 is endocytosed more frequently in the side of the growth cones exposed to higher Wnt5a level.

To further investigate whether the distribution of activated aPKC, a downstream target of Wnt5a and Dishevelled2, also shows asymmetry in the Wnt5a gradient, we stained for activated aPKC marker (phospho-PKC $\zeta(T 410)$ ). We found that active aPKC (phospho-PKC $\zeta$ (T410)) was enriched in the proximal side exposed to higher Wnt5a level than the distal side in the growth cones (Fig. $8 E, F$ ). Together, these results suggest that Wnt5a gradient causes asymmetric endocytosis of Frizzled 3 and aPKC activation in the growth cones, which may be essential for growth cone turning toward higher Wnt5a concentration (Fig. 8G).

\section{Discussion}

An emerging theme in growth cone guidance is that PCP signaling pathway may be a widely used mechanism for mediating directional control of axon growth (Zou, 2012). How PCP signaling components direct growth cone turning is still poorly known. We show here that Firzzled3 endocytosis through the tips of growth cone filopodia, tightly regulated by its phosphorylation state, is essential for Wnt-mediated growth cone turning (Fig. $8 G$ ). Our earlier studies showed that aPKC, a key component of apical-basal polarity (A-BP) signaling, also mediates Wnt attractions and anterior-posterior guidance of commissural axons (Wolf et al., 2008). We found here that aPKC inhibits Dishevelled1-induced Frizzled3 hyperphosphorylation and thus 
A

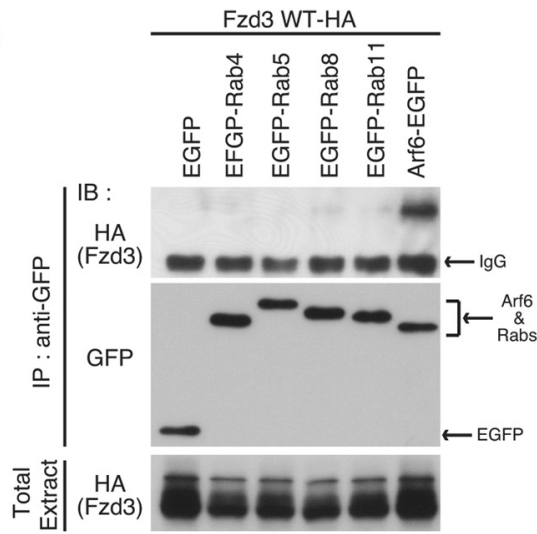

D

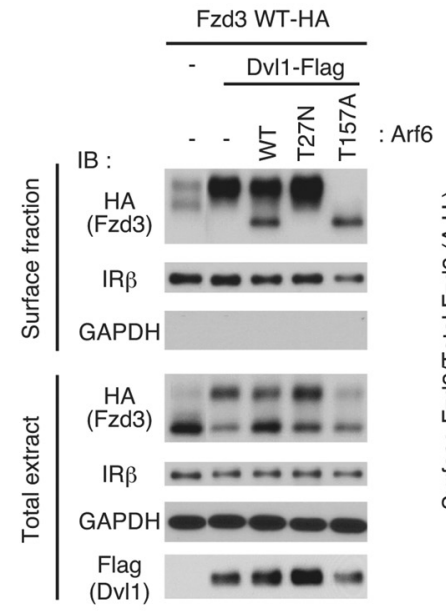

$\mathbf{F}$
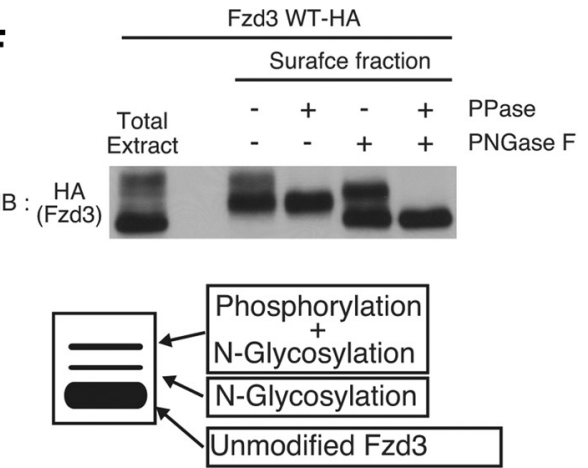

B
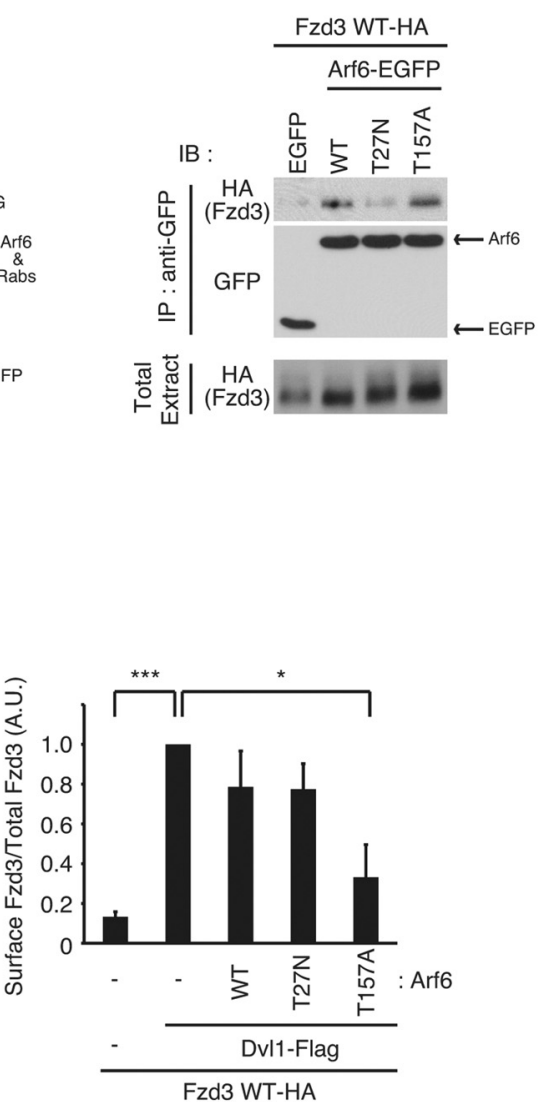

G

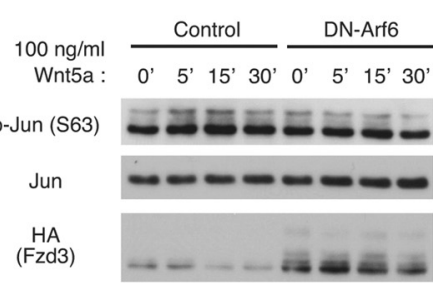

C

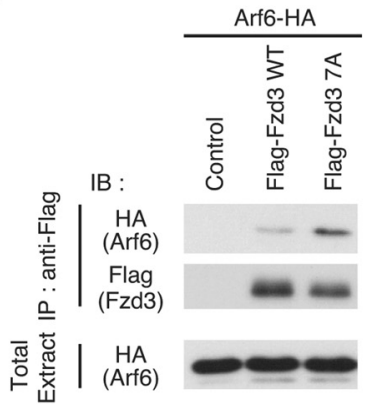

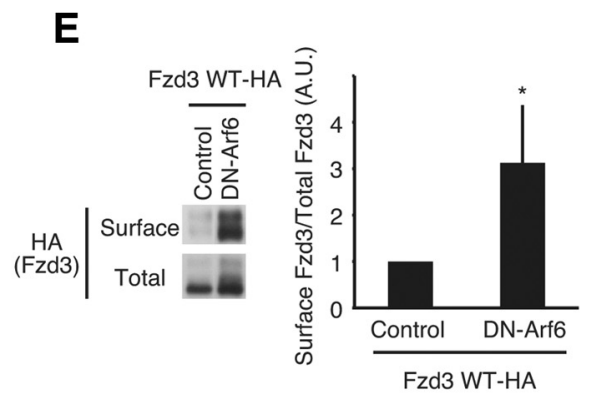

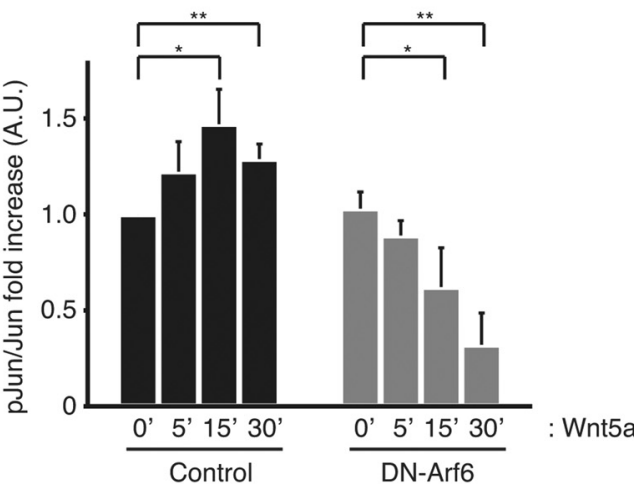

Figure 6. Arf6 mediates Frizzled3 endocytosis and Wnt-PCP signaling. A, Arf6 interacts with Frizzled3. B, Frizzled3 interacts with Arf6 WT and T157A mutant, and less with T27N mutant. C, Arf6 preferentially interacts with Frizzled3 (7A) mutant. D, Arf6 T157A mutant suppresses Dishevelled1-induced Frizzled3 hyperphosphorylation and cell-surface accumulation. GAPDH is used for cytoplasmic marker and IR $\beta$ (Insulin receptor $\beta$ ) is for cell-surface marker. $\boldsymbol{E}$, DN-Arf6 induces Frizzled3 cell-surface accumulation. $\boldsymbol{F}$, Modification of Frizzled3 on cell surface. $\boldsymbol{G}$, Arf6 activity is required for Wnt5a-induced PCP signal activation. Quantification data in $\boldsymbol{D}, \boldsymbol{E}$, and $\boldsymbol{G}$, are the mean \pm SD of values from three independent experiments. ${ }^{*} p<0.05,{ }^{* *} p<0.01,{ }^{* * *} p<0.001$.

promotes Frizzled 3 endocytosis. Activated aPKC is also localized asymmetrically in growth cones in a Wnt gradient (Fig. 8G). A-BP and PCP are two fundamental cellular properties, essential to the morphology and function of many classes of cells (Karner et al., 2006; Wang and Nathans, 2007; Zallen, 2007; Knoblich, 2008). These cell polarity qualities are particularly prominent in epithelial tissues, along perpendicular axes, but are also widely present in tissues from other germ layers (Karner et al., 2006; Zallen, 2007; Goodrich and Strutt, 2011). The findings that these two cell polarity signaling pathways are essential for axon guidance opens a new avenue to study growth signaling mechanisms leading to steering (Zou, 2012).
The growth cone is divided into distinct compartments of individual filopodia (peripheral domain) and the central domain. We show that Dishevelled1 blocks Wnt/PCP signaling by keeping Frizzled3 in hyperphosphorylated state and on plasma membrane (Fig. 7E). Dishevelled2, which activates aPKC, inhibits Dishevelled1. Therefore, once PCP signaling is activated in a subset of filopodia, as marked by high levels of Vangl2, PCP signal can be amplified by this antagonistic interaction between Dishevelled2 and Dishevelled1 (Fig. 7F). This positive feedback mechanism amplifies Wnt-PCP signaling and may help sensitize the growth cone in shallow gradients of Wnts along the anteriorposterior axis. 
A

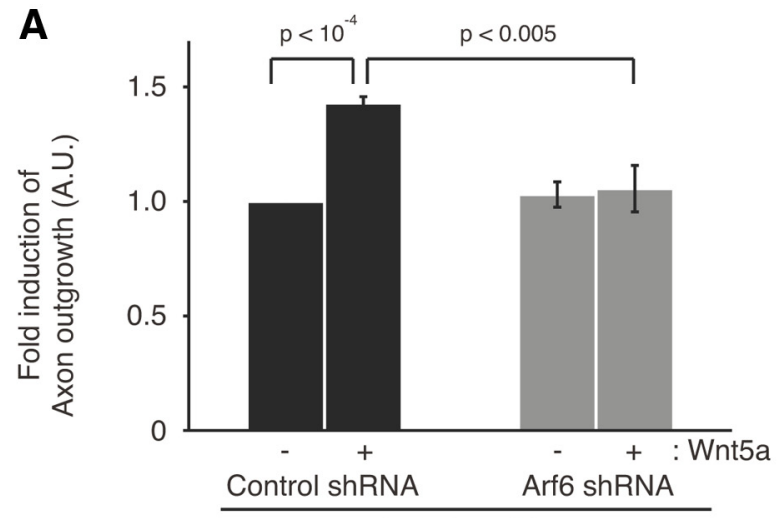

+ Frizzled3-mCherry

C

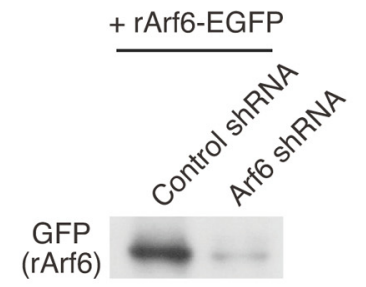

Calnexin

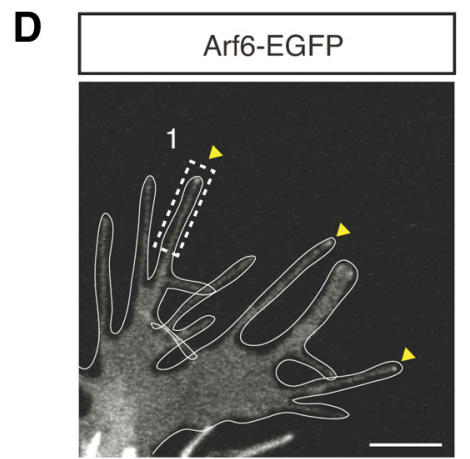

$\mathbf{E}$

Celsr3

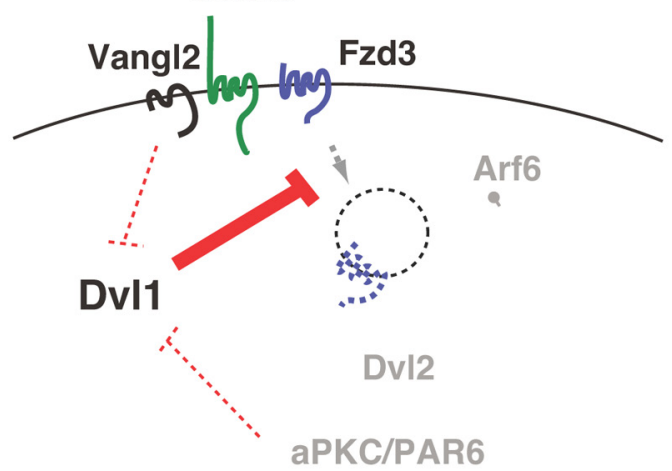

PCP

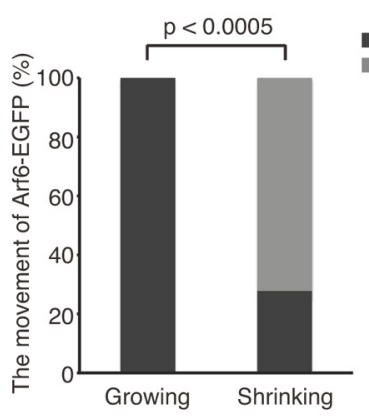

B
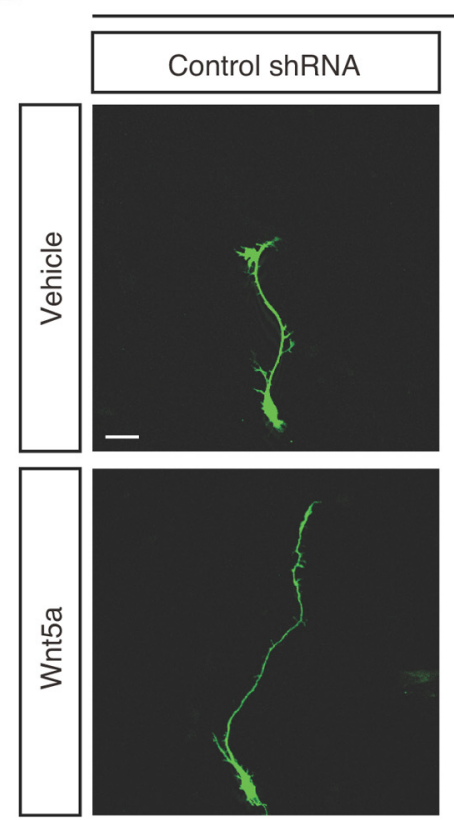

+ Frizzled3-mCherry
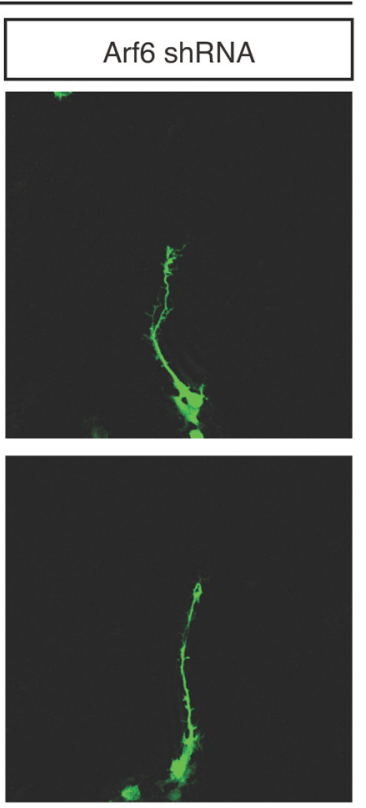

- Inward movement

No inward movement

\section{F Celsr3}

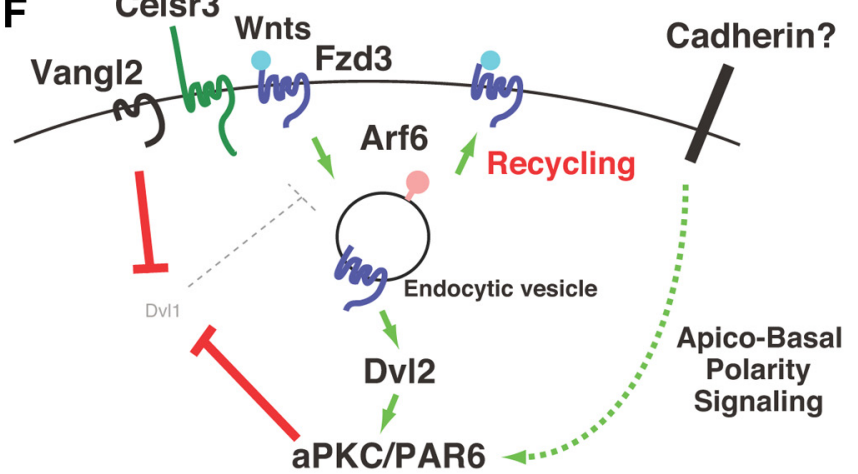

PCP

Figure 7. Arf6 mediates Wnt5a-induced commissural axon outgrowth. $A$, Arf6 is required for Wnt5a-induced commissural axon outgrowth. Quantification data are the mean \pm SD of values from three independent experiments. $\boldsymbol{B}$, Images of commissural neurons expressing control shRNA or Arf6 shRNA in the absence or presence of Wnt5a. Scale bar, $10 \mu \mathrm{m}$. $\boldsymbol{C}$, The efficiency of Arf6 knockdown. D, Arf6-EGFP trafficking in the commissural growth cones. Arf6-EGFP accumulates at the tips of filopodia in the commissural axonal growth cones. The inward movement of Arf6-EGFP vesicles is observed more frequently in the growing filopodia than in the shrinking filopodia. $\boldsymbol{E}, \boldsymbol{F}$, A model for signal amplification. In the absence of Wnt, Dishevelled 1 inhibits Frizzled3 endocytosis by inducing Frizzled3 hyperphosphorylation. Upon Wnt binding, Frizzled3 is endocytosed and activates the Dishevelled2-aPKC/PAR6 axis. aPKC then inhibits Dishevelled1. In the mean time, Vangl2 also inhibits Dishevelled1. As a result, more Frizzled3 is endocytosed and activates downstream signaling, which then in turn further removes inhibition by Dishevelled1. Arf6 mediates Frizzled3 endocytosis and its essential roles in PCP signaling activation. Meanwhile, A-BP polarity signaling pathway is also involved in aPKC regulation, suggesting A-BP signaling also regulates PCP signaling. 
A

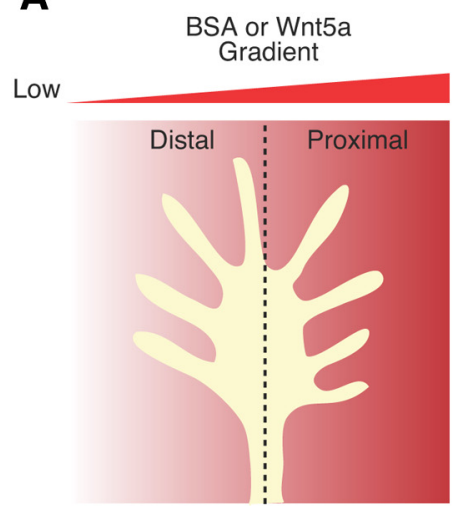

C

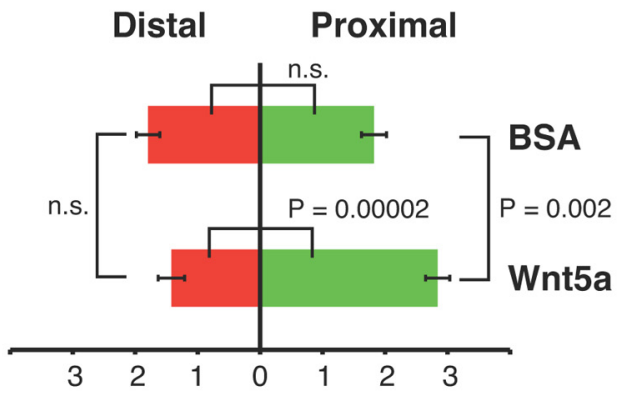

Number of Fzd3/AP-2 colocalized tips

E

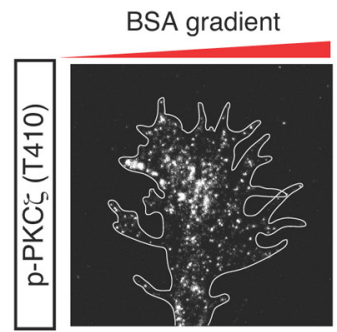

Wnt5a gradient

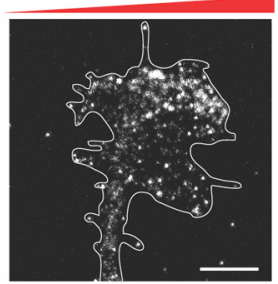

G

B
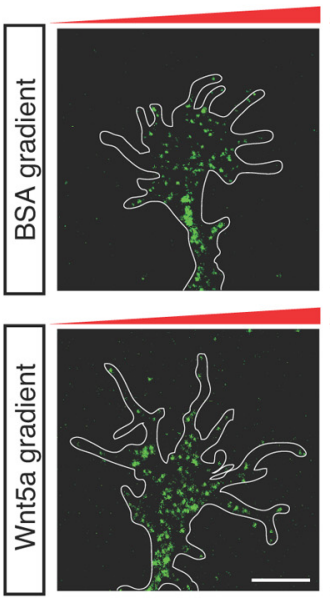

D
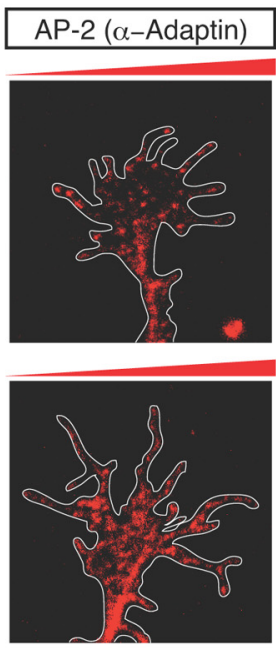
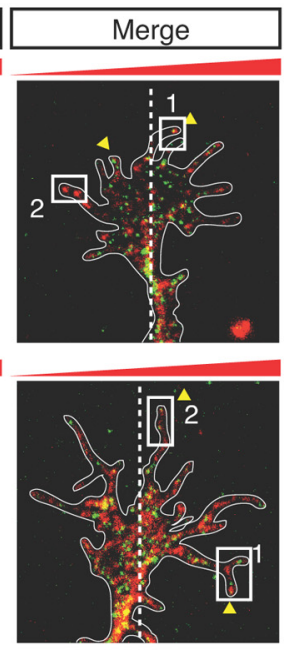

Wnt5a

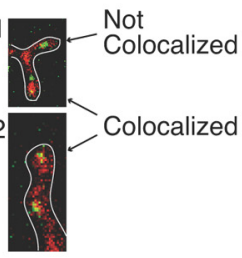
BSA

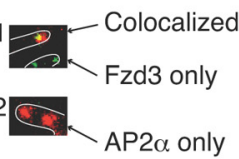

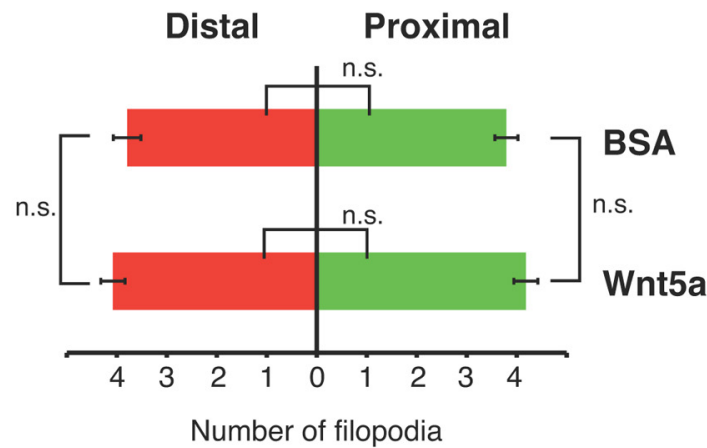

$\mathbf{F}$

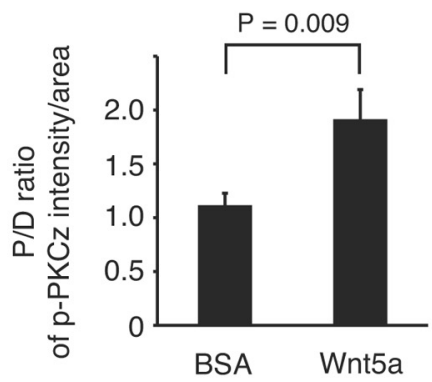

Wnts

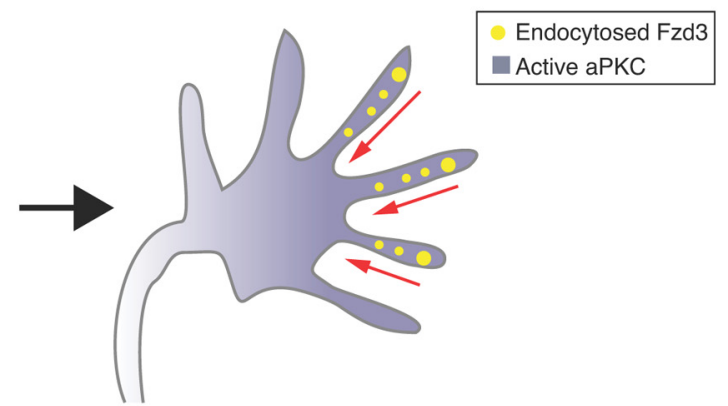

Figure 8. Frizzled 3 endocytosis in a Wnt5a gradient. $A$, Schematics of experimental design to expose commissural axon growth cones to Wnt5a gradient using the Dunn chamber. Growth cones perpendicular to the gradient were selected and divided into a "proximal" and "distal" side. B, Immunostaining of endogenous Frizzled3 and $\alpha$-Adaptin in the dissociated commissural axonal growth cones exposed to BSA or Wnt5a gradient in the Dunn chamber. Endogenous Frizzled3 is colocalized with $\alpha$-Adaptin at the tip of filopodia more frequently in the proximal side. Scale bar, 5 $\mu \mathrm{m}$. C, Quantification data about the colocalization of Frizzled 3 and AP-2 at the tips of filopodia in $\boldsymbol{B}$. Data are the mean \pm SEM. $\boldsymbol{D}$, Quantification data about the number of filopodia in $\boldsymbol{B}$. Data are the mean \pm SEM. $E$, Immunostaining of phospho-PKC $\zeta(T 410)$ in the dissociated commissural axonal growth cones exposed to BSA or Wnt5a gradient in the Dunn chamber. Phospho-PKC $\zeta$ is more abundant in the proximal side. Scale bar, $5 \mu \mathrm{m}$. $F$, Quantification data about P/D ratio of phospho-PKC $\zeta$ (T410) intensity/area in $\boldsymbol{B}$. Data are the (Figure legend continues.) 
In searching for small GTPases, which may regulate Frizzled3 trafficking, we found that Arf6 regulates Frizzled3 endocytosis and preferably binds to nonphosphorylated Frizzled3. Arf6 is required for Wnt5a-mediated PCP signaling and commissural axon outgrowth promoted by Wnt/PCP signaling. Arf6 is known to mediate rapid endocytosis. This is also consistent with our observation that Frizzled 3 is very rapidly endocytosed via the tips of growth cones. This may be necessary for growth cones to bring in information from the environment for making decisions for the direction of turning (Fig. 8G). Remarkably, using Arf6-EGFP as an indicator for endocytic vesicles, we found that the inward movement of Arf6 vesicles correlates with filopodia extension. This provides additional support to the hypothesis that Frizzled endocytosis and inward movement bring in PCP signal to likely regulate actin and microtubule dynamics.

In commissural axon turning, growth cones are organized in a plane parallel to the floor plate and turn anteriorly as a group after crossing the floor plate. The growth cones of commissural neurons which are born at the same time are within close proximity. It takes hours (8-9) to cross the midline and an additional $1-2 \mathrm{~h}$ to turn anteriorly (Zou lab, unpublished results). Filopodia of commissural axon growth cones have plenty of time to interact with each other. Therefore, this global anterior turning of a "sheet" of commissural axons is highly reminiscent of planar polarity in epithelia (Zou, 2012). If such growth cone-growth cone interaction exits and is important for proper turning, Ceslr3 would be a strong candidate for mediating this interaction. If this actually occurs, a sheet of axons can sample a longer distance along the anterior-posterior axis, thus a greater concentration drop than individual growth cones. This is an interesting plausible mechanism of how shallow gradient of guidance cues are efficiently defected.

In addition to the spinal cord commissural axons, serotonergic and dopaminergic axons, originating from the hindbrain and midbrain, respectively, also orient their axons along the anteriorposterior axis under the control of Wnt/planar cell polarity signaling (Fenstermaker et al., 2010; Blakely et al., 2011). Studies in Drosophila also revealed consistent mechanisms that PCP signaling is essential for proper growth and guidance of mushroom body neuron and dorsal cluster neuron axons (Mrkusich et al., 2011; Shimizu et al., 2011). Additional studies in invertebrates showed that PCP signaling can regulate neurite formation in $\mathrm{Cae}$ norhabditis elegans and axon branch extension in Drosophila (Sanchez-Alvarez et al., 2011; Ng, 2012). A Wnt receptor, Ryk/ Derailed, first found to be a conversed repulsive receptor in Drosophila and rodents, has been shown recently as a regulator of PCP signaling (Yoshikawa et al., 2003; Liu et al., 2005; Keeble et al., 2006; Schmitt et al., 2006; Liu et al., 2008; Li et al., 2009; Andre et al., 2012 Macheda et al., 2012). These studies suggest that PCP signaling may be a commonly used pathway for directional control of axon growth and thus making Wnt/PCP signaling an excellent system to study growth cone steering mechanisms (Zou, 2012).

\section{$\leftarrow$}

(Figure legend continued.) mean \pm SEM. G, A working hypothesis of commissural axonal growth cone turning according to Wnt gradients. In the absence of Wnts gradient, Frizzled 3 is endocytosed randomly through the filopodia tips and active aPKC is distributed uniformly (left growth cone). In a Wnt gradient, Frizzled3 endocytosis occurs more frequently in the proximal side and causes more aPKC activation (middle growth cone).

\section{References}

Andre P, Wang Q, Wang N, Gao B, Schilit A, Halford MM, Stacker SA, Zhang X, Yang Y (2012) The Wnt coreceptor Ryk regulates Wnt/planar cell polarity by modulating the degradation of the core planar cell polarity component Vangl2. J Biol Chem 287:44518-44525. Medline

Bashaw, GJ, Klein R (2010) Signaling from axon guidance receptors. Cold Spring Harb Perspect Biol 2:a001941. CrossRef Medline

Blakely BD, Bye CR, Fernando CV, Horne MK, Macheda ML, Stacker SA, Arenas E, Parish CL (2011) Wnt5a regulates midbrain dopaminergic axon growth and guidance. PLoS One 6:e18373. CrossRef Medline

Charron F, Stein E, Jeong J, McMahon AP, Tessier-Lavigne M (2003) The morphogen sonic hedgehog is an axonal chemoattractant that collaborates with netrin-1 in midline axon guidance. Cell 113:11-23. CrossRef Medline

Fenstermaker AG, Prasad AA, Bechara A, Adolfs Y, Tissir F, Goffinet A, Zou Y, Pasterkamp RJ (2010) Wnt/Planar cell polarity signaling controls the anterior-posterior organization of monoaminergic axons in the brainstem. J Neurosci 30:16053-16064. CrossRef Medline

Goodrich LV, Strutt D (2011) Principles of planar polarity in animal development. Development 138:1877-1892. CrossRef Medline

Jackson CL, Casanova JE (2000) Turning on ARF: the Sec7 family of guanine-nucleotide-exchange factors. Trends Cell Biol 10:60-67. CrossRef Medline

Karner C, Wharton KA, Carroll TJ (2006) Apical-basal polarity, Wnt signaling and vertebrate organogenesis. Semin Cell Dev Biol 17:214-222. CrossRef Medline

Keeble TR, Halford MM, Seaman C, Kee N, Macheda M, Anderson RB, Stacker SA, Cooper HM (2006) The Wnt receptor Ryk is required for Wnt5a-mediated axon guidance on the contralateral side of the corpus callosum. J Neurosci 26:5840-5848. CrossRef Medline

Knoblich JA (2008) Mechanisms of asymmetric stem cell division. Cell 132: 583-597. CrossRef Medline

Li L, Hutchins BI, Kalil K (2009) Wnt5a induces simultaneous cortical axon outgrowth and repulsive axon guidance through distinct signaling mechanisms. J Neurosci 29:5873-5883. CrossRef Medline

Liu Y, Shi J, Lu CC, Wang ZB, Lyuksyutova AI, Song XJ, Zou Y (2005) Ryk-mediated Wnt repulsion regulates posterior-directed growth of corticospinal tract. Nat Neurosci 8:1151-1159. CrossRef Medline

Liu Y, Wang X, Lu CC, Kerman R, Steward O, Xu XM, Zou Y (2008) Repulsive Wnt signaling inhibits axon regeneration after CNS injury. J Neurosci 28:8376-8382. CrossRef Medline

Lyuksyutova AI, Lu CC, Milanesio N, King LA, Guo N, Wang Y, Nathans J, Tessier-Lavigne M, Zou Y (2003) Anterior-posterior guidance of commissural axons by Wnt-frizzled signaling. Science 302:1984-1988. CrossRef Medline

Macheda ML, Sun WW, Kugathasan K, Hogan BM, Bower NI, Halford MM, Zhang YF, Jacques BE, Lieschke GJ, Dabdoub A, Stacker SA (2012) The Wnt receptor Ryk plays a role in mammalian planar cell polarity signaling. J Biol Chem 287:29312-29323. CrossRef Medline

Matsumoto Y, Irie F, Inatani M, Tessier-Lavigne M, Yamaguchi Y (2007) Netrin-1/DCC signaling in commissural axon guidance requires cellautonomous expression of heparan sulfate. J Neurosci 27:4342-4350. CrossRef Medline

Mrkusich EM, Flanagan DJ, Whitington PM (2011) The core planar cell polarity gene prickle interacts with flamingo to promote sensory axon advance in the Drosophila embryo. Dev Biol 358:224-230. CrossRef Medline

Ng J (2012) Wnt/PCP proteins regulate stereotyped axon branch extension in Drosophila. Development 139:165-177. CrossRef Medline

Sanchez-Alvarez L, Visanuvimol J, McEwan A, Su A, Imai JH, Colavita A (2011) VANG-1 and PRKL-1 cooperate to negatively regulate neurite formation in Caenorhabditis elegans. PLoS Genet 7:e1002257. CrossRef Medline

Santy LC (2002) Characterization of a fast cycling ADP-ribosylation factor 6 mutant. J Biol Chem 277:40185-40188. CrossRef Medline

Santy LC, Casanova JE (2001) Activation of ARF6 by ARNO stimulates epithelial cell migration through downstream activation of both Racl and phospholipase D. J Cell Biol 154:599-610. CrossRef Medline

Sato A, Yamamoto H, Sakane H, Koyama H, Kikuchi A (2010) Wnt5a regulates distinct signalling pathways by binding to Frizzled2. EMBO J 29: 41-54. CrossRef Medline

Schmitt AM, Shi J, Wolf AM, Lu CC, King LA, Zou Y (2006) Wnt-Ryk 
signalling mediates medial-lateral retinotectal topographic mapping. Nature 439:31-37. Medline

Shafer B, Onishi K, Lo C, Colakoglu G, Zou Y (2011) Vangl2 promotes Wnt/planar cell polarity-like signaling by antagonizing Dvl1-mediated feedback inhibition in growth cone guidance. Dev Cell 20:177-191. CrossRef Medline

Shimizu K, Sato M, Tabata T (2011) The Wnt5/planar cell polarity pathway regulates axonal development of the Drosophila mushroom body neuron. J Neurosci 31:4944-4954. CrossRef Medline

Tissir F, Bar I, Jossin Y, De Backer O, Goffinet AM (2005) Protocadherin Celsr3 is crucial in axonal tract development. Nat Neurosci 8:451-457. Medline

Wang Y, Nathans J (2007) Tissue/planar cell polarity in vertebrates: new insights and new questions. Development 134:647-658. CrossRef Medline

Wang Y, Zhang J, Mori S, Nathans J (2006) Axonal growth and guidance defects in Frizzled3 knock-out mice: a comparison of diffusion tensor magnetic resonance imaging, neurofilament staining, and genetically directed cell labeling. J Neurosci 26:355-364. CrossRef Medline

Wolf AM, Lyuksyutova AI, Fenstermaker AG, Shafer B, Lo CG, Zou Y (2008) Phosphatidylinositol-3-kinase-atypical protein kinase C signaling is required for Wnt attraction and anterior-posterior axon guidance. J Neurosci 28:3456-3467. CrossRef Medline

Yam PT, Langlois SD, Morin S, and Charron F (2009) Sonic hedgehog guides axons through a noncanonical, Src-family-kinase-dependent signaling pathway. Neuron 62:349-362. CrossRef Medline

Yamamoto A, Nagano T, Takehara S, Hibi M, Aizawa S (2005) Shisa promotes head formation through the inhibition of receptor protein maturation for the caudalizing factors, Wnt and FGF. Cell 120:223-235. CrossRef Medline

Yoshikawa S, McKinnon RD, Kokel M, Thomas JB (2003) Wnt-mediated axon guidance via the Drosophila Derailed receptor. Nature 422:583-588. CrossRef Medline

Yu A, Rual JF, Tamai K, Harada Y, Vidal M, He X, Kirchhausen T (2007) Association of Dishevelled with the clathrin AP-2 adaptor is required for Frizzled endocytosis and planar cell polarity signaling. Dev Cell 12:129 141. CrossRef Medline

Zallen JA (2007) Planar polarity and tissue morphogenesis. Cell 129:10511063. CrossRef Medline

Zhou L, Bar I, Achouri Y, Campbell K, De Backer O, Hebert JM, Jones K, Kessaris N, de Rouvroit CL, O'Leary D, Richardson WD, Goffinet AM, Tissir F (2008) Early forebrain wiring: genetic dissection using conditional Celsr3 mutant mice. Science 320:946-949. CrossRef Medline

Zou Y (2012) Does planar cell polarity signaling steer growth cones? Curr Top Dev Biol 101:141-160. CrossRef Medline

Zou Y, Stoeckli E, Chen H, Tessier-Lavigne M (2000) Squeezing axons out of the gray matter: a role for slit and semaphorin proteins from midline and ventral spinal cord. Cell 102:363-375. CrossRef Medline 